\title{
Dissecting the integrative antioxidant and redox systems in plant mitochondria. Effect of stress and S-nitrosylation
}

\author{
Juan J. Lázaro ${ }^{1}$, Ana Jiménez ${ }^{2}$, Daymi Camejo ${ }^{2}$, Iván Iglesias-Baena ${ }^{1}$, María del Carmen Martí ${ }^{2+}$, \\ Alfonso Lázaro-Payo ${ }^{1}$, Sergio Barranco-Medina ${ }^{1+}$ and Francisca Sevilla ${ }^{2} *$ \\ ' Department of Biochemistry and Cellular and Molecular Biology of Plants, Estación Experimental del Zaidín, Consejo Superior de Investigaciones Científicas, \\ Granada, Spain \\ ${ }^{2}$ Department of Stress Biology and Plant Pathology, Centro de Edafología y Biología Aplicada del Segura, Consejo Superior de Investigaciones Científicas, \\ Murcia, Spain
}

\section{Edited by:}

Jose A. Traverso, Consejo Superior de Investigaciones Científicas, Spain

\section{Reviewed by:}

Christine Helen Foyer, University of Leeds, UK

Toru Hisabori, Tokyo Institute of Technology, Japan

\section{*Correspondence:}

Francisca Sevilla, Department of Stress Biology and Plant Pathology, Centro de Edafología y Biología Aplicada del Segura, Consejo Superior de Investigaciones Científicas, Campus Universitario de Espinardo, E-30100 Murcia, Spain

e-mail:fsevilla@cebas.csic.es

\section{${ }^{\dagger}$ Present address:}

Sergio Barranco-Medina, Department of Biochemistry and Molecular Biology, Saint Louis University, St. Louis, MO, USA; María del Carmen Marti, Department of Plant Sciences, University of Cambridge, Cambridge, UK
Mitochondrial respiration provides the energy needed to drive metabolic and transport processes in cells. Mitochondria are a significant site of reactive oxygen species (ROS) production in plant cells, and redox-system components obey fine regulation mechanisms that are essential in protecting the mitochondrial integrity. In addition to ROS, there are compelling indications that nitric oxide can be generated in this organelle by both reductive and oxidative pathways. ROS and reactive nitrogen species play a key role in signaling but they can also be deleterious via oxidation of macromolecules. The high production of ROS obligates mitochondria to be provided with a set of ROS scavenging mechanisms. The first line of mitochondrial antioxidants is composed of superoxide dismutase and the enzymes of the ascorbate-glutathione cycle, which are not only able to scavenge ROS but also to repair cell damage and possibly serve as redox sensors. The dithiol-disulfide exchanges form independent signaling nodes and act as antioxidant defense mechanisms as well as sensor proteins modulating redox signaling during development and stress adaptation. The presence of thioredoxin (Trx), peroxiredoxin (Prx) and sulfiredoxin (Srx) in the mitochondria has been recently reported. Cumulative results obtained from studies in salt stress models have demonstrated that these redox proteins play a significant role in the establishment of salt tolerance. The Trx/Prx/Srx system may be subjected to a fine regulated mechanism involving post-translational modifications, among which $S$-glutathionylation and $S$-nitrosylation seem to exhibit a critical role that is just beginning to be understood. This review summarizes our current knowledge in antioxidative systems in plant mitochondria, their interrelationships, mechanisms of compensation and some unresolved questions, with special focus on their response to abiotic stress.

Keywords: abiotic stress, ascorbate-glutathione cycle, mitochondria, peroxiredoxin, signaling, $S$-nitrosylation, sulfiredoxin, thioredoxin

\section{INTRODUCTION}

Plant mitochondria host some of the most important biological processes, i.e, oxidative phosphorylation, citric acid cycle and fatty acid oxidation. Based on their physiological relevance, mitochondria are involved in underpinning cellular proliferation, plant growth, development and death (Millar et al., 2011). Although chloroplasts and peroxisomes are the major ROS producers in plant cells under light periods (Foyer and Noctor, 2003), mitochondrial metabolism significantly accounts for the total ROS generation (Noctor et al., 2007). Overall, complexes I and III of the electron transport chain (ETC) are the main sites of ROS production and about $1-5 \%$ of the total consumed oxygen is converted into hydrogen peroxide $\left(\mathrm{H}_{2} \mathrm{O}_{2}\right.$; Moller, 2001).

Initially, mitochondrial ROS were considered as an undesirable by product with deleterious effects. Higher ROS amounts resulting from uncontrolled ROS generation can cause oxidative stress by damaging cellular components and affecting organelle integrity. A growing number of publications now recognize the implication of
ROS in many other cellular processes, including its proposed role as signaling molecules under oxidative conditions (Dat et al., 2000; Mittler et al., 2011). The condition of signaling molecules implies a tight control of ROS-antioxidants' interplay in the different cell compartments, and the activation of signaling pathways by ROS responsive regulatory genes has been suggested as contributing to plant tolerance toward different stresses (Schwarzländer and Finkemeier, 2013). Therefore, the response of plants to ROS is dose dependent (Veal et al., 2007). Under stress conditions, the presence of ROS is not always a symptom of cellular dysfunction, but rather a signal to modulate transduction pathways through mitogen-activated protein kinases (MAPK) and transcription factors (Jaspers and Kangasjärvi, 2010). In mammals, this signaling process is present in several diseases and shows the crosstalk between multiple transcription factors and the redox-regulating protein Trx (Burke-Gaffney et al., 2005). In plants, a much less studied system, the involvement of Trx in redox signaling is being considered (Zaffagnini et al., 2012b). 
Besides ROS, plant mitochondria have also emerged as an important site for nitric oxide production by two main pathways: a mitochondrial nitrite reducing activity whose site of $\mathrm{NO}^{\bullet}$ generation remains uncertain (Planchet et al., 2005), and the oxidation of L-arginine by an elusive nitric oxide synthase (NOS; Guo and Crawford, 2005). Formation of ROS in junction with $\mathrm{NO}^{\bullet}$ may present a danger in the mitochondria. To maintain the cellular redox homeostasis and avoid an oxidative stress that could cause molecular damage, plant mitochondria possess a set of antioxidant enzymes such as manganese superoxide dismutase (Mn-SOD), enzymes of the ascorbate-glutathione cycle and enzymes of the Trx/Prx/Srx system (Sevilla et al., 1982; Jiménez et al., 1997; Barranco-Medina et al., 2008b). These antioxidant scavengers respond to the stress situations (Martí et al., 2011) by regulating the level of ROS and modulating the redox signaling.

Along with ROS, reactive nitrogen species (RNS) are critical factors in signaling, by working as second messengers. The signaling process can be indirectly exerted by molecules that have suffered the oxidative damage by a reversible change in the redox state. Posttranslational modifications (PTMs) of redox cysteine residues of targets proteins constitute a secondary mitochondrial retrograde regulation (MRR) and can modulate ROS and RNS signaling (Hartl and Finkemeier, 2012). Among them, S-glutathionylation and $S$-nitrosylation have emerged as novel regulators in cell signaling and response to stress conditions (Zaffagnini et al., 2012a; Camejo etal., 2013a). Protein oligomerization and reversible overoxidation of cysteine residues add a further step into the redox regulation (Barranco-Medina et al., 2009; Iglesias-Baena et al., 2010).

In this work we dissect the different aspects of the redox regulation of plant mitochondria, with special emphasis on the ascorbate-glutathione cycle and Trx/Prx/Srx system under stress.

\section{MITOCHONDRIA ARE ESSENTIAL SOURCES OF ROS AND RNS}

Mitochondria are highly dynamic, metabolically active cell organelles. From a functional point of view, ETC in plant mitochondria differs from its animal counterpart in two additional pathways: alternative $\mathrm{NAD}(\mathrm{P}) \mathrm{H}$ dehydrogenases (type II $\mathrm{NDH}$ ) and alternative oxidase (AOX). Both of these non-protonpumping pathways could function as "safety valves" to limit ROS production by maintaning the ETC relatively oxidized (Moller, 2001; Rasmusson and Wallström, 2010; Millar et al., 2011). Plants ETC consists of four main complexes, some of them organized into supracomplexes (Dudkina et al., 2006). Supplementary to the NADH dehydrogenase, complex I and the flavoprotein complex II, the inner mitochondrial membrane contain type II NDH that bypass complex I and supply electrons to the ubiquinone pool and do not contribute to the generation of the proton motive force needed for ATP synthesis. Besides the usual cytochrome c oxidase (complex IV), a non-phosphorylating AOX is present. This enzyme bypasses the electron flow from complex III and IV, coupling the oxidation of ubiquinol with the reduction of oxygen to water, dissipating the energy as heat and lowering the ADP/O ratio. Shunting electrons through this pathway is important in energy-rich plants cells for primary and secondary metabolism, as well as for oxidation of excess carbohydrate (Rasmusson and Wallström, 2010). The expression of AOX and type II NDH, both of nuclear encoding, is increased during ETC inhibition by mitochondria to nucleus signaling (Van Aken et al., 2009a; Hartl and Finkemeier, 2012; Leister, 2012). In this process, organellar redox state and ROS metabolism have been poproposed as sources for retrograde signals which could trigger gene expression responses and provide a metabolic flexibility which, during stress conditions, play an important role in the acclimation of plants (Rhoads and Subbaiah, 2007; Woodson and Chory, 2008)

\section{ROS PRODUCTION}

A key feature of mitochondrial biochemistry is the unavoidable production of ROS, with complex I and complex III being the major sites (Noctor et al., 2007). Under specific conditions ROS may be produced at complex II site, in the course of reverse electron transport (Turrens, 2003). ROS production is enhanced under conditions of high matrix $\mathrm{NADH}^{+} / \mathrm{NAD}$. On the other hand, increased membrane potential correlates with more highly reduced ETC components, so raising the probability of single electron leak to oxygen and of $\mathrm{O}_{2}^{\bullet-}$. This superoxide can, in turn, act as substrate for the generation of secondary ROS such as $\mathrm{H}_{2} \mathrm{O}_{2}$ and hydroxyl radical $(\bullet \mathrm{OH})$. The magnitude of membrane potential is dependent on the activity of the energy-dissipating systems, and on the oxidative phosphorylation. Hence, when ADP is being actively phosphorylated, membrane potential and ROS are lower than when ADP is limiting. Increased energy dissipation can similarly be achieved by artificial uncouplers, uncoupling proteins (UCPs; Moller, 2001; Finkel, 2011; Collins et al., 2012) and by the plant mitochondria potassium channel (PmitoK $\mathrm{ATP}_{\mathrm{P}}$ ) which can be stress-activated through several mechanisms, including activation by ROS, so indicating the fine regulation of this biochemical pathway. Dissipation of membrane potential directly by these components may be important in tissues with low AOX expression and/or activities (Trono et al., 2004). Similarly, in mammalian, $\mathrm{H}_{2} \mathrm{O}_{2}$ treatment of myoblast and cardiomyocyte mouse cells, increased the expression of the transcription factor $\mathrm{Nrf} 2$ that promoted the expression of the UCP, UCP3 decreasing ROS production and preventing cell death (Anedda et al., 2013).

Reactive oxygen species accumulation in mitochondria could also be influenced by PTM of respiratory complexes (Taylor et al., 2003; Beer et al., 2004), activity of alternative NADPH dehydrogenases (Rasmusson and Wallström, 2010) and modification of antioxidant systems and oxygen concentration (Jiménez et al., 1998). The relative importance of the different factors could be tissue specific (Noctor et al., 2007).

\section{NO• PRODUCTION}

In plants, two major enzymatic pathways are proposed to participate in $\mathrm{NO}^{\bullet}$ formation: oxidation of L-arginine to L-citruline by a NOS like enzyme and reduction of nitrite to $\mathrm{NO}^{\bullet}$ by a nitrate reductase (NR; Neill et al., 2003; Fröhlich and Durner, 2011; Gupta et al., 2011). In the past decade, the presence of NOS-like activity in plant peroxisomes was demonstrated. However, the characterization of such an enzyme is unresolved (del Río et al., 2002). To date, in contrast with mammalian tissue, the production of $\mathrm{NO}^{\bullet}$ by a NOS-like enzyme in plant mitochondria remains elusive (Gupta and Kaiser, 2010). The reduction of nitrite to $\mathrm{NO}^{\bullet}$ by the mitochondrial ETC contributes to ATP production under 
hypoxic conditions. $\mathrm{NO}^{\bullet}$ production by a mitochondrial nitrite reducing activity has yet been detected in different photosynthetic sources and mitochondria isolated from roots of diverse plants species. These activities depend on the expression and/or activity of $\mathrm{NR}$, since this enzyme is the main source of nitrite in plants (Wulff et al., 2009). Pharmacological evidences based on inhibitor sensitivity, suggests that complex III, cytochromec oxidase (COX) and $\mathrm{AOX}$ are all involved in nitrite to $\mathrm{NO}^{\bullet}$ reduction, although a clear mechanism is established only for cytochrome oxidase under hypoxia. However, this may become increasingly important as partial pressures of oxygen are reduced from the ambient level (Gupta and Igamberdiev, 2011).

Nitric oxide can react immediately with superoxide originated from ETC, to form peroxynitrite $\left(\mathrm{ONOO}^{-}\right)$. Through this reaction, superoxide probably plays a role in regulating free $\mathrm{NO}^{\bullet}$ level (Leitner et al., 2009). The protonated form of $\mathrm{ONOO}^{-}$, the peroxynitrous acid $\mathrm{ONOOH}$ (pKa 6.8) is involved in many deleterious reactions, such as oxidation of DNA, lipids: protein thiols and iron clusters (Vandelle and Delledonne, 2011). Paradoxically, in systems where the toxicity comes predominantly from more toxic molecules such as peroxides, $\mathrm{NO}^{\bullet}$ may elicit protective activity against them (Van Breusegem et al., 2001).

\section{REDOX REGULATION IS AN ESSENTIAL FEATURE OF PLANT MITOCHONDRIAL FUNCTION}

Mitochondrial ROS generation can be perpetuated throughout a broad number of reactions yielding different reactive species that serve as substrates for the specific antioxidant enzymes. The mitochondrial antioxidant system, through superoxide and peroxides detoxification, has a pivotal role affecting redox signaling.

\section{Mn-SOD AND ENZYMES OF THE ASCORBATE-GLUTATHIONE CYCLE Mn-SOD}

In plants, Mn-SOD (Figure 1) appears as a tetrameric isoenzyme initially purified and characterized in Pisum sativum leaves (Sevilla et al., 1982), and located in both, mitochondria and peroxisomes (del Río et al., 1992). Numerous proteins have been identified as being dual targeted, mainly to plastids and mitochondria although around ten-twelve have been described as nuclear and plastidial, or mitochondrial and peroxisomal as MnSOD (Duchêne and Giegé, 2012). Mitochondrial and peroxisomal $\mathrm{Mn}-\mathrm{SOD}$ expression is regulated differently in processes like leaf senescence, where post-translational events may regulate the enzymatic activity of the peroxisomal enzyme (del Río et al., 2003; Palma et al., 2006). Mn-SOD is important in providing protection against oxidative stress in these organelles, so avoiding the formation of more dangerous ${ }^{\bullet} \mathrm{OH}$ radicals and controlling $\mathrm{H}_{2} \mathrm{O}_{2}$ production. Defects in mitochondrial function are associated to a large number of different phenotypes. It has been reported that the lack of mitochondrial SODs in Caenorhabditis elegans mutants, in contrast to that reported in yeast or animals (Kirby et al., 2002), reduces not longevity but growth (Van Raamsdonk and Hekimi, 2009). In this case, a reduction in the metabolic energy observed could afford different explanations like the reported induction of uncoupling mechanisms, which reduced ROS generation in mitochondria, the decrease of the membrane potential and/or activity of the ETC. A similar reduction in growth has been described for Mn-SOD mutants in plants; in this case the respiration rate was not affected but the mitochondrial redox balance and some of the tricarboxylic acid (TCA) cycle enzymes were altered. Unexpectedly, Mn-SOD mutants displayed an increased antioxidant capacity, suggesting the existence of a retrograde pathway trying to compensate the lack of this antioxidant enzyme (Morgan et al., 2008). Reduction in growth is a general phenotypic characteristic in mitochondrial dysfunction and it may exhibit the interconnection established between mitochondrial metabolism and photosynthetic carbon assimilation. A complementary hypothesis has adduced the crosstalk between redox signaling and hormonal pathways regulating growth inhibition (Schwarzländer and Finkemeier, 2013).

\section{ASC-GSH cycle}

As a result of the $\mathrm{O}_{2}^{\bullet-}$ dismutation, the newly formed $\mathrm{H}_{2} \mathrm{O}_{2}$ can be decomposed by the mitochondrial peroxidase activities dependent on the antioxidants: (I) ascorbate (ASC) for the hemo-containing enzyme ascorbate peroxidase (APX; Figure 1), (II) the thiol reductant glutathione (GSH) for the glutathione peroxidases (GPX) and (III) the thioredoxin/peroxiredoxin system (Trx/Prx). The generated oxidized forms of ASC are then reduced by the FADcontaining monodehydroascorbate reductase (MDHAR) in an $\mathrm{NAD}(\mathrm{P}) \mathrm{H}$-dependent manner and dehydroascorbate reductase (DHAR) using GSH as electron donor. Oxidized GSSG is reduced by the flavoprotein glutathione reductase (GR) and oxidized by thioredoxin reductase (NTR), both in an NADPH-dependent manner (Noctor and Foyer, 1998; Barranco-Medina et al., 2007; Martí et al., 2009). Accordingly, the antioxidant and redox systems in mitochondria depend on an adequate supply of $\mathrm{NAD}(\mathrm{P}) \mathrm{H}$ that is maintained by transhydrogenases in the mitochondrial membrane, as well as the enzymes isocitrate dehydrogenase and malate dehydrogenase in the matrix (Rasmusson and Moller, 1991).

The first publications reporting the presence of the some components of the so-called ASC-GSH cycle in mitochondria (Figure 1) appeared in 1981 and 1990 with MDHAR and GR of potato and pea mitochondria, respectively (Arrigoni et al., 1981; Edwards etal., 1990). The final proof of principle of a complete cycle in plant mitochondria, similar to that in chloroplast (Foyer and Halliwell, 1976), was later described in pea leaves (Jiménez et al., 1997). Using enzymatic latency assays, APX activity was located outside of the inner mitochondrial membrane whereas MDHAR was highly latent in intact mitochondria and was membrane-bound. These findings suggested that the electron acceptor and donor sites of this redox protein are not on the external side of the mitochondrial membrane. DHAR and GR were found in the mitochondrial matrix and the antioxidants ASC and GSH were present as demonstrated by chromatographic techniques. Biochemical data also indicated that the mitochondrial APX activity resulted in at least two isoezymes with different substrate specificity and sensibility to inhibitors when compared to that found in peroxisomes and chloroplasts (Jiménez et al., 1998). The possible presence of the isoenzymes linked to the inner face of the external membrane was described by Chew et al. (2003). The membrane location of APX and MDHAR suggested a dual complementary function for both enzymes: they could reoxidize endogenous NADH to maintain a constant supply of $\mathrm{NAD}^{+}$for 


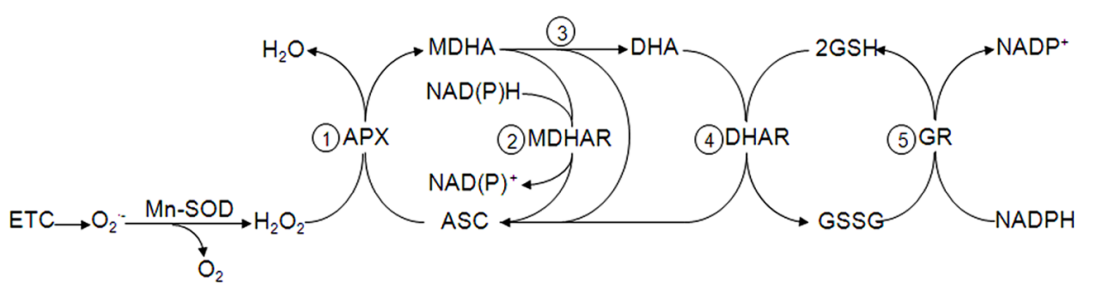

FIGURE 1 | Mitochondrial ascorbate-glutathione cycle. The hydrogen peroxide in the mitochondria produced by ETC is reduced by APX at the expense of ASC to produce MDHA (step 1) that is either reduced to ASC (step 2) or disproportionated to DHA and ASC (step 3). DHAR reduces DHA using GSH as electron donor (step 4), which is regenerated by GR and NADPH (step 5) mitochondrial metabolism (Douce et al., 2001) and protection against $\mathrm{H}_{2} \mathrm{O}_{2}$ (del Río et al., 1998; Chew et al., 2003). Thus, both enzymes also contribute to the signal transduction processes that lead to specific gene expression by regulating the mitochondrial and cytosolic concentration of the diffusible signaling molecule $\mathrm{H}_{2} \mathrm{O}_{2}$ (del Río et al., 1996). The presence of the ASC-GSH cycle in nitrogen-fixing legumes root nodules has been proved as well as its protective activity toward mitochondrial-derived radicals in sensitive spots like the hemo o leghemoglobin groups (Puppo et al., 2005).

Pea GR and Arabidopsis MDHAR were described as dualtargeted proteins in plant cells (Creissen et al., 1995; Obara et al., 2002). In Arabidopsis, two genes encode GR, called GR1 encoding a cytosolic and peroxisomal protein, and GR2, found in chloroplast and mitochondria, which is lethal when it is inactivated at an early stage of embryo formation (Meyer et al., 2012). Using biochemical, targeting and proteomic assays, the presence of the ASC-GSH cycle was corroborated in mitochondria of Arabidopsis by Chew et al. (2003). These authors proposed an integrative coordination between chloroplast and mitochondria through the dual targeting of proteins such as APX, MDHAR, and GR gene products to both organelles, while DHAR only had a mitochondrial localization. It was postulated that the coordination between plastids and mitochondria might occur by the dual targeting rather than subtle retrograde signaling (Millar et al., 2001; Chew et al., 2003).

The presence of one isozyme of APX on the intermembrane space side of the inner membrane is convenient for the use of the ASC generated in this location. ASC is produced by the terminal enzyme L-galactono-1,4-lactone dehydrogenase (GalLDH) also attached to the inner membrane and located in the mitochondrial complex I, and its presence is required for the stability of the complex (Pineau et al., 2008). GalLDH activity is highly dependent on the availability of oxidized cytochrome $\mathrm{c}$ from the mitochondrial respiratory chain and is also regulated by redox controls such as glutathionylation (Bartoli et al., 2000; Millar et al., 2003; Leferink et al., 2009). In addition to the reductive GSH dependent DHA reduction, ASC regeneration may also be attributed to the respiratory ETC (Szarka et al., 2007) or linked to other redox compounds as glutaredoxin (Grx) and Trx systems (Potters et al., 2002; Meyer et al., 2012).

Levels and redox state of ASC have been shown to be involved in the modulation of photosynthesis by mitochondrial metabolism and a complementation has been suggested between AOX pathway and ASC to protect photosynthesis against photoinhibition. Respiration-dependent changes in mitochondrial ASC synthesis could regulate retrograde signaling as a common signal from both mitochondria and chloroplasts (Talla et al., 2011). A good example of such an inter-organelle communication is the ASC produced in the mitochondria and then transported into the apoplast. In contrast to GSH, ASC appears to exert its greatest influence by setting thresholds for apoplastic and cytoplasmic signaling (Munné-Bosch et al., 2013).

The second abundant antioxidant in plant tissues is the thiol compound GSH, participating in the detoxification of ROS, heavy metals and xenobiotics and in the cell cycle regulation (Rouhier et al., 2008; Foyer and Noctor, 2009; Diaz Vivancos et al., 2010). GSH is synthesized in plastids and cytosol and then transported to mitochondria, although the nature and regulation of these transporters is still unclear. The dicarboxylate/2-oxoglutarate transporter in the inner mitochondrial membrane has been proposed as a potential candidate, as reported in animals (Wilkins et al., 2012). Immunolabelling studies have proved the presence of GSH in both, mitochondria and chloroplast containing about $15-25 \%$ and $62-75 \%$ respectively of the total pool of GSH (Fernández-García et al., 2009).

Under non-stress conditions, GSH is presented mainly in its reduced form, but stress conditions and/or senescence and detoxification of ROS can lead to its oxidation impacting in the cellular redox state (Jiménez et al., 1998; Vanacker et al., 2006; Noctor et al., 2012). GSH is also emerging as a player in the intracellular redox potential regulation, protection and signaling through PTMs such as glutathionylation of specific target proteins (Zaffagnini et al., 2012b) involving Cys residues. A link between complex I (CI) activity and GSH has also been shown in CI Arabidopsis mutants insensitive to a GSH biosynthesis inhibitor and with higher levels of GSH, implying an as yet unexplained effect of mitochondrial respiration on GSH homeostasis (Koprivova et al., 2010).

\section{Mn-SOD, AOX AND ENZYMES OF THE ASCORBATE-GLUTATHIONE CYCLE IN STRESS RESPONSE AND SIGNALING}

Abiotic stress can produce contradictory effects depending on the specie, tissue analyzed and the developmental stage of the plant. The plant acclimation also depends on the application time and strength of the treatment. Mitochondria are central organelles in setting cellular redox balance and homeostasis (Noctor et al., 2007). Increased ROS production in the mitochondria along with 
the antioxidant defense orchestrating the cellular stress response, including salinity, has been well documented (Hernández et al., 2000; Mittova et al., 2003; Taylor et al., 2009). ROS production in mitochondria has been reported to increase under salinity and drought conditions. A stimulation of $\mathrm{O}_{2}^{\bullet-}$ generation dependent on NADH- and succinate has been reported in plants under salinity, with a higher increase in sensitive cultivars than in tolerant plants (Hernández et al., 1993; Pastore et al., 2007). Furthermore, oxidative damage induced by $\mathrm{NaCl}$ stress can affect different cellular targets selectively: complex I of the ETC was found to be damaged via oxidative stress while complex II directly by salt (Hamilton and Heckathorn, 2001). In this context, changes in ROS levels caused by the perturbation of the respiratory complex I: have been proposed to trigger a mitochondrial retrograde signal (Rhoads and Subbaiah, 2007).

The adaptive response of plants induced by salt stress is well documented; in Arabidopsis, of 300 salt stress-induced genes, more than half had a predicted mitochondrial localization (Heazlewood et al., 2007). In general, an induced expression of antioxidant defense genes is usually correlated with enhanced salt stress tolerance (Hernández etal., 2000; Attia et al., 2008) although the molecular mechanisms involved in the regulation of this induction remains unrevealed (Foyer and Noctor, 2005). Moreover, changes at a transcript level did not usually correlate well with changes in protein responsive to stress, and post-transcriptional mechanisms are believed to play an important role in defining the mitochondrial stress response (MSR; Van Aken etal., 2009b).

Alternative oxidase in one of the components of MSR and has been used as a model system to study MRR (Van Aken et al., 2009b). Arabidopsis AOX1a mutant plants have been described as exihibiting altered antioxidant transcripts of both chloroplasts and mitochondria, when exposed to a combination of drought and light stress (Filipou et al., 2011). Interestingly, the ABI4 transcription factor involved in the chloroplast-nucleus signaling is responsible for the transcriptional regulation of $A O X 1 a$ (Giraud et al., 2009). Transcripts encoding AOX genes, mainly AOX1a and $A O X 1 d$, are highly responsive to stress including salinity. In fact, plants constitutively over-expressing Ataox $1 a$, with increased AOX capacity, showed lower ROS formation and improved growth in salinity conditions (Smith et al., 2009). Yet, discrepancies in AOX expression and in vivo activity have also been reported, and recently discussed (Ribas-Carbó et al., 2005, Rasmusson et al., 2009). Overall, the current knowledge in AOX attributes it an important role in stress adaptation in plants while its participation in cell re-programming under salinity stress has been proposed (Clifton et al., 2006).

Mitochondrial Mn-SOD, has also been reported to modulate its expression in response to salinity stress (Kaminaka et al., 1999; Dai et al., 2009; Rubio et al., 2009), undergoing an overexpression in tolerant cultivars while decreasing in salt sensitive ones (Hernández etal., 2000). This seminal observation has gained additional support by the fact that the overexpression of $\mathrm{Mn}$ SOD in transgenic Arabidopsis, poplar, rice and tomato plants showed increased salt tolerance (Tanaka et al., 1999; Wang et al., 2004, 2007, 2010a). The study of the changes in Mn-SOD protein revealed that, in tolerant pea plants, this protein was maintained with the duration of the salt treatment (Camejo et al., 2013a), while proteomic studies have shown that Mn-SOD of Arabidopsis accumulated during $\mathrm{NaCl}$ stress (Jiang et al., 2007). Also, mitochondria from salt-tolerant and salt-sensitive wheat cultivars subjected to salinity stress showed augmented levels of Mn-SOD and AOX, along with changes in cysteine synthase required for GSH formation. The coordinated increase in Mn-SOD and AOX proteins is thought to prevent the over-reduction of the mitochondrial ubiquinone pool, so lowering the content of superoxide in this organelle. The marked overexpression of these enzymatic systems responds to the specific adjustment of the cells in response to the oxidative stress. The fact that the vast majority of the non-redox proteome remained unchanged under saline stress strengthens this hypothesis (Jacoby et al., 2010). These authors suggest that the differences in proteomes of wheat varieties correlated with whole-plant salinity tolerance.

The heterogeneity of the antioxidant systems response under stress is manifested in numerous occasions. Each isoform of the same antioxidant enzyme in the different cell compartments can present a specific profile activity in lines/cultivars differing in salt tolerance (Olmos et al., 1994; Ashraf, 2009). A correlation between expression, protein and activity levels is usually found for MnSOD. Salt-tolerant tomato, pea and wheat cultivars have shown higher activity of mitochondrial Mn-SOD compared with a saltsensitive cultivar (Hernández et al., 1993; Sairam and Srivastava, 2002; Mittova etal., 2003). This is not the case of peroxisomal $\mathrm{Mn}-\mathrm{SOD}$ isoform since it was not induced in response to salt stress either in the tolerant or in the sensitive pea plants (Corpas et al., 1993).

As previously noted, GSH and ASC have a strong influence in gene expression (Munné-Bosch et al., 2013). The balance of reduced to oxidized forms of both antioxidants is crucial for the cell to sense oxidative stress and to respond accordingly (Mullineaux and Rausch, 2005; Foyer and Noctor, 2009, 2011). Consequently, the ASC/GSH pathway plays an essential role to cope the oxidative stress imposed by environmental stress including salinity (Hernández et al., 2000, 2001; Pallanca and Smirnoff, 2000; Gómez et al., 2004; Sharma and Dubey, 2005; Hefny and Abdel-Kader, 2009; Noctor et al., 2012). The existence of balance mechanisms to maintain ASC and/or GSH-dependent processes and related signaling response in specific compartments, when their respective contents are depleted, has been well established (Foyer and Noctor, 2011). In contrast, information on mitochondrial ASC and GSH contents and redox state is scarcely reported and their accurate role in mitochondria under abiotic stress is not well stated.

Information on the enzymes responsible to maintain and regulate the reduced/oxidized state of mitochondrial ASC and GSH, shows that the regulation of their gene expression presents high plasticity, and is an important component in the response of plants to stressful conditions.

The expression of $A P X$ encoding genes is modulated by various environmental stimuli, such as drought and salt (Hernández et al., 2000; Menezes-Benavente et al., 2004; Gill and Tuteja, 2010; Bonifacio et al., 2011). Very scarce information has been published on the APX mitochondrial isoform. In mitochondria from Oriza sativa, $\triangle$ OsAPX6 expression remained unchanged against 
salt stress (Teixeira et al., 2006), while other works have reported an induction for the same isoenzyme in rice (Yamane et al., 2010). The discrepancy in regulation for this and other APX genes might be due to the absence of standardized conditions of measurements, since each group used different cultivars, organs, plant age and growth conditions which, as related above, have an important contribution in plant stress response. The beneficial effects of APX have been documented in plants overexpressing this enzyme in chloroplast, peroxisomes and cytosol displaying an enhanced plant tolerance to salt and water deficit and ameliorating inducedoxidative injury (Badawi etal., 2004; Lu et al., 2007; Wei-Feng et al., 2008). A compensatory mechanism in rice mutant double silenced for cytosolic APXs by other antioxidant enzymes has been described, making the mutants able to cope with salt, heat, high light and methyl viologen stress, similar to non-transformed plants (Bonifacio et al., 2011).

Enzyme activity comparisons have proved that mitochondrial APX and GR are constitutively higher in salt-tolerant wheat cultivar than in sensitive plants although none responded to salinity (Sairam and Srivastava, 2002). This response was different in mitochondria from tolerant pea plants, in which APX and MDHAR activities appeared early increased at mild salt stress and progressively increased under high salt concentrations, whereas GR and Mn-SOD were induced only after severe salinity. In chloroplasts and peroxisomes, these isoenzymes responded differently than in mitochondria, although stromatic APX, but not thylakoidal, was significantly and progressively increased, together with DHAR in response to the severity of the salt stress (Corpas et al., 1993; Gómez et al., 1999, 2004). The study in tomato revealed a decreased oxidative stress in a tolerant salt cultivar which, in part, was attributed to induced activities of Mn-SOD and mitochondrial APX, as previously commented in pea, as well as to increases of both ASC and GSH content in mitochondria, by a yet-unexplained mechanism (Mittova et al., 2004). Scarce information exists on the possible relation of these activities with the mitochondrial MDHAR and DHAR expression. Nonetheless, a compensative overexpression of different cytosolic and chloroplastic MDHAR and DHAR can enhance plant tolerance against various abiotic stresses (Gill and Tuteja, 2010) including salinity in tobacco, potato and Arabidopsis (Eltayeb et al., 2007, 2011; Wang et al., 2010b).

Similarly, the regulation of the GR has been proved to efficiently respond to different stresses (Creissen et al., 1994). A cytosolic GR gene was found induced in a pea salt tolerant, but not in the salt-sensitive, cultivar (Hernández etal., 2000) and the induction of the symplastic GR activity was higher in the tolerant plants, at the same time as increased DHAR and MDHAR activities. A putative role for all these enzymes in the control of symplastic/apoplastic ASC content was described (Hernández etal., 2001). The overexpression of GR has been shown to improve tolerance to oxidative stress, leading in tobacco and poplar to a higher ASC content in leaves (Aono et al., 1993; Foyer et al., 1995).

All together, these results suggest a fine-tuning for chloroplasts and mitochondrial signaling mechanisms to coordinate the response of these antioxidant enzymes for the acclimation of plants to salinity conditions.

\section{Trx/Prx/Srx SYSTEM Thioredoxins}

Thioredoxins (Trxs) are ubiquitous small proteins involved in the reduction of disulphide bonds of other proteins through a dithiol-disulfide exchange. They have a conserved active site WCG/PPC with reductive properties to regulate specifically target proteins. Plants, unlike bacteria and animals, contain several nuclear encoded Trx genes. In Arabidopsis thaliana, at least 20 $\operatorname{Tr} x$ genes have been reported with different location (Collin et al., 2004; Meyer et al., 2012). The presence of Trx in plant mitochondria was shown by Laloi et al. (2001) in Arabidopsis, and was classified as Trxo type (AtTrxo1), although an additional mitochondrial $h$-type Trx was also localized in poplar (Gelhaye et al., 2004). More recently, a pea Trxol was described in both mitochondria and nucleus under normal conditions (Martí et al., 2009) while the localization of a nuclear Trx type $h$ had been shown only under oxidative conditions in germinating wheat seeds (Serrato et al., 2001; Serrato and Cejudo, 2003; Pulido et al., 2009). Mitochondrial and cytosolic Trxs are reduced by a homodimeric FAD-NTR that utilizes NADPH (Figure 2), while chloroplastic ones use a ferredoxin-NTR system (Gelhaye et al., 2005). Two genes encoding NTR have been found in Arabidopsis: AtNTRB, which expresses the mitochondrial form and AtNTRA, expressing the cytosolic one (Reichheld et al., 2005; Tovar-Méndez et al., 2011). A new NADPH NTR (NTRC) has been demonstrated to exist in chloroplasts and non-photosynthetic plastids (Serrato et al., 2004; Kirchsteiger et al., 2012). NTRC have both, NTR and Trx, domains in the same polypeptide chain and reduces chloroplast 2-Cys Prx without the assistance of Trx (Pérez-Ruiz et al., 2006; Pulido et al., 2010). As far as we know, the high abundance of different Trx types in the cell as well as the redundant coexistence of different Trxs within the same organelle may reflect the presence of differential redox pathways for each. The specific function, protein-protein interaction and redox-network implication for the cited Trxs is far from being elucidated. Moreover, the high diversity in plants Trxs when compared with humans might add an additional antioxidant support in plants.

Although the extensive research in the last two decades has revealed diverse aspects of Trxs in plants, very little is known about the mitochondrial Trx function. It has been suggested that it is related to mitochondrial redox regulation and AOX (Balmer et al., 2004; Gelhaye et al., 2004; Martí et al., 2009; Yoshida et al., 2013) and, the detoxification of ROS via a mitochondrial PrxIIF has also been proposed (Barranco-Medina et al., 2008b). Application of the mutant affinity column approach by using cytoplasmic or

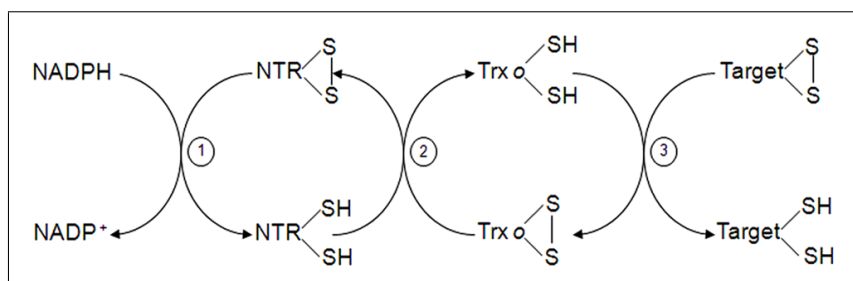

FIGURE 2 | Trx system in mitochondria. Mitochondrial Trxo is reduced by NADPH-dependent TR (steps 1 and 2). Reduced Trxo can reduce in turn mitochondrial target proteins (step 3). 
chloroplastic forms of mutated Trxs, led to a systematic screening of Trx targets and thus, Balmer et al. (2004) were able to identify 50 potential Trx targets in mitochondria that covered major metabolic pathways. However, mutant PsTrxo1C37S in a proteomic assay with pea mitochondria only identified nine potential PsTrxol targets (Martí et al., 2009). Among the PsTrxo1-linked proteins there are components of the glycine decarboxylase complex and serine hydroxymethyl transferase (SHMT), key enzymes in photorespiration, and the alpha-subunit of the mitochondrial ATP synthase, which links Trxol with the control of ATP synthesis. Besides, the elongation factor $\mathrm{Tu}$, that promotes the GTP-dependent binding of aminoacyl-tRNA to the ribosome, thiosulfate sulfurtransferase, mercaptopyruvate sulfurtransferase involved in sulfur metabolism and the drought stress related short-chain alcohol dehydrogenase were also identified.

Biochemical characterizations have reported that PsTrxol is able to activate two additional enzymes, the antioxidant PrxIIF (see below) and the respiratory enzyme AOX (Martí et al., 2009). Recently, Yoshida et al. (2013), using a similar methodology have found 101 Trx targets in mitochondria. Among them, the enzymes cited before have also been reported. A more detailed confirmation analysis by additional approaches is required to evaluate all these proteins as "true" targets, helping to understand the in situ functional significance of these Trx-target interactions.

Alternative oxidase has been identified in Arabidopsis as a protein of the inner mitochondrial membrane with an intramolecular disulfide bond (Winger et al., 2007). This protein is encoded by a small gene family, whose members have been shown to be both tissue-and development specific. AOX has not been identified as a Trx target using Trx-linked resins, although it can be both reduced and activated by mitochondrial thioredoxin PtTrxh 2 by using its effector pyruvate (Gelhaye et al., 2004; Umbach et al., 2006). Similarly, PsTrxo1 specifically reduced pea mitochondrial AOX homodimers and produced the activation of oxygen consumption by this AOX pathway, using a NADPH/NTR system (Martí et al., 2009). Our comparative study of the published literature reveals the higher ability of PsTrxol to activate AOX in pea mitochondria compared with that in soybean organelle, presenting NADPH/NTR/PsTrxol as a highly effective system in the activation of the AOX pathway in pea. As reported, AOX plays an important role in preventing or minimizing ROS formation in cells (Maxwell et al., 1999; Yip and Vanlerberghe, 2001; Millar et al., 2011). Thus, we hypothesize that Trxo1, through the control of the reduced levels of AOX, might regulate respiratory metabolism and associated reactions. Trxol through activation of PrxIIF and AOX, could also play a role in linking ROS and redox signaling in mitochondria.

Several proteins have a dual localization to mitochondria and nucleus (Duchêne and Giegé, 2012) and a signaling function for mitochondrial biogenesis has been speculated. In pea leaves, PsTrxo1 was also found in nuclei with an apparent molecular mass of $20.6 \mathrm{kDa}$, corresponding to the protein translated and driven to the nuclei without the removal of the mitochondrial N-terminal targeting signal (Martí et al., 2009). Some plant Trxs have been found in the nucleus under stress conditions, i.e., Trx h typically located in the cytosol, has been reported to accumulate in the nucleus of aleurone and scutellum cells during germination
(Serrato and Cejudo, 2003; Pulido et al., 2009). The function of PsTrxol in the nucleus is unknown although could be related to transcriptional regulation through oxidation protection of heterochromatin as proposed for the mammalian PRDX5 (Kropotov etal., 2006), the regulation of activity of several transcription factors (Hirota et al., 1997) and/or the control of apoptosis signalregulated kinase 1 activity (Saitoh et al., 1998). Further studies seeking to identify functional targets for PsTrxo1 in the nucleus are needed to learn more about new physiological roles of this Trxo1 in plant cell.

\section{Peroxiredoxins}

Peroxiredoxins (Prxs) are thiol-based peroxidases involved in peroxide detoxification and play an important role in signaling (Wood et al., 2003). Prxs share a common catalytic mechanism where, by reducing peroxide, the catalytic active site Cys is oxidized to a sulfenic acid, which then forms a disulphide bond with a resolving Cys that is reduced by the Trx-NTR and NADPH system. Prxs reduce hydrogen peroxide and alkyl hydroperoxides to water and the corresponding alcohol, respectively. They were initially identified in yeast (Kim et al., 1988) and then in mammals and humans, with six different human Prxs (PrxI-VI) grouped in three types (Chae et al., 1994). The presence of plant Prxs was first discovered by Baier and Dietz (1996) and their classification does not correspond with the nomenclature established for human Prxs. Plant Prxs are divided into four subgroups based on the number and position of the conserved cysteine residues, namely 2-Cys Prx, type II Prx, Prx Q, and 1-Cys Prx, with different subcellular locations.

Type II Prxs are dimeric enzymes with varying molecular mass, isoelectric points and subcellular localization and have been proposed as primary sensors for hydrogen peroxide (Rhee et al., 2005). They were discovered in mammalian as a type of Prxs that forms an intramolecular disulfide as a reaction intermediate. In mammals, only one type II Prx (Prx V), with mitochondrial localization, has been found (Seo et al., 2000). In plants, three type II Prxs have a cytosolic (PrxIIB, C and D), one a chloroplastic (PrxIIE) and one a mitochondrial localization (PrxIIF; Horling et al., 2002). Plant mitochondrial PrxIIF is highly conserved between different species and contains the two cysteine-residues characteristic of type II Prx at positions 59 (peroxidatic Cys) and 84 (resolving Cys) of the mature protein (Finkemeier et al., 2005; Barranco-Medina et al., 2007).

While the disulfide bridge formed in typical 2-Cys Prx, after hydroperoxide reduction, is intermolecular, in atypical type II Prx it is intramolecular (Seo et al., 2000). The catalytic cycle of PrxIIF consists of three steps (Figure 3): (1) the nucleophilic attack of the peroxide by the conserved peroxidatic Cys $\left(\mathrm{Cys}-\mathrm{S}_{\mathrm{P}} \mathrm{H}\right)$ that is oxidized to sulfenic acid (Cys- $\left.\mathrm{S}_{\mathrm{P}} \mathrm{OH}\right),(2)$ the formation of the disulfide by attack of the free thiol of the resolving Cys $\left(\right.$ Cys $\left.-S_{R} H\right)$ to release water, and (3) the regeneration of the thiol form by mitochondrial Trxo, Grx and GSH as electron donors (Finkemeier et al., 2005; Gama et al., 2007; Barranco-Medina et al., 2008b). Rouhier et al. (2002) proposed a reaction mechanism for a cytosolic type II Prx from poplar in which only one of the two cysteinyl residues is involved in catalysis. Furthermore, Barranco-Medina et al. (2007), using two mutated variants, demonstrated that both Cys residues are essential for efficient catalysis. The interaction between Trxo 


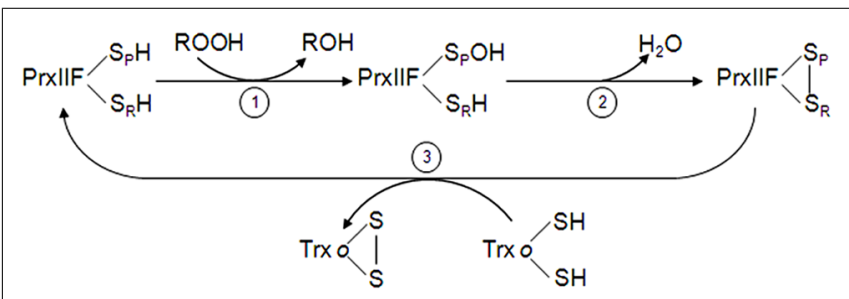

FIGURE 3 | Reaction mechanism of mitochondrial PrxIIF. PrxIIF is oxidized to its sulfenic form in the reduction of peroxides (step 1). PrxIIF-SOH forms an intramolecular disulfide bridge (step 2) that is reduced by the mitochondrial Trxo system (step 3).

and PrxIIF has been demonstrated with recombinant proteins and using C36S Trxo variant (Barranco-Medina et al., 2008b; Martí etal., 2009). The catalytic efficiency of plant PrxIIF (Rouhier and Jacquot, 2005; Barranco-Medina et al., 2007) is significantly higher than of 2-Cys Prx (König et al., 2003; Bernier-Villamor et al., 2004).

Structural studies of atypical Prxs have shown that PrxIIF dimerizes like typical 2-Cys Prx, but its dimerization is based on A-type, instead of B-type, interfaces (Echalier et al., 2005; Karplus and Hall, 2007). Moreover, the presence of high molecular weight species has been established (Evrard et al., 2004). Unlike 2-Cys Prx, that occurs as decamers, pea mitochondrial PrxIIF crystallizes as hexamers (Barranco-Medina et al., 2006) which are favored in oxidant conditions, but dissociate to dimers upon reduction (Barranco-Medina et al., 2008b). The presence of peroxidatic Cys was critical for hexamer formation whereas substitution of resolving Cys did not impact the oligomeric pattern (Barranco-Medina et al., 2007). By analogy with the dimer-decamer transition of the typical 2-Cys Prx (König et al., 2002; Wood et al., 2003; BernierVillamor et al., 2004; Barranco-Medina et al., 2008a, 2009), the dimer-hexamer transition in atypical PrxIIF displays a functional switch that could be involved in signaling (Barranco-Medina et al., 2008b).

Mitochondrial PrxIIF was one of the last identified antioxidants to be discovered in this organelle with functions in the reduction of hydrogen peroxide, playing also a chaperone-like activity (Finkemeier et al., 2005; Barranco-Medina et al., 2008b). In spite of the fact that mitochondria are one of the major sites of ROS generation in plant cells, and in contrast to other cellular compartments, PrxIIF is the only Prx type present in mitochondria. Its comparable activity with other Prxs and the presence of other efficient antioxidants in mitochondria bear witness to the auxiliary function of PrxIIF as $\mathrm{H}_{2} \mathrm{O}_{2}$ scavenger (Finkemeier et al., 2005). The recently reported signaling/chaperone functions of PrxIIF are no longer trivial and deserve special attention.

Recently, the overoxidized form of PrxIIF has been shown to work as a non-transcriptional rhythmic marker. The circadian clock is an endogenous $24 \mathrm{~h}$ oscillator regulating many critical biological processes in plants. One of the key characteristics of the circadian clock is that it is buffered against temperature, maintaining an approximately $24 \mathrm{~h}$ rhythm over a broad physiological temperature range. The existence of overoxidized PrxIIF and its retroreductive sulfiredoxin ( $\mathrm{Srx}$ ) systems raises the question as to whether or not this plant mitochondrial antioxidant could work as circadian clock (O'Neill and Reddy, 2011). This feature might be crucial to plants growing in a constantly changing environment. This unaddressed hypothesis is a challenge to future investigations to elucidate new functions of plant Prxs.

\section{Sulfiredoxins}

Under oxidative conditions, Prxs undergo a transient oxidation of their cysteine residues from thiol to sulfenic acid and further stable disulfide bridges, which are regenerated to the thiolic forms by Trxs interaction (Figure 4). Under severe oxidative stress, Prxs rapidly overoxidize to the sulfinic (Cys- $\left.\mathrm{S}_{\mathrm{P}} \mathrm{O}_{2} \mathrm{H}\right)$ and sulfonic $\left(\right.$ Cys $\left.-\mathrm{S}_{\mathrm{p}} \mathrm{O}_{3} \mathrm{H}\right)$ form, locking the enzyme in a permanent inactive state which was primarily hypothethized to serve as an internal indicator of the hyperoxidative conditions inside the cells. The oxidation of the sulfenic acid to sulfinic acid was thought to be an irreversible step (Yang et al., 2002) until Woo et al. (2003) reported that the sulfinic form, produced under high levels of $\mathrm{H}_{2} \mathrm{O}_{2}$, was reduced to the catalytically active thiol form. These seminal observations served to suggest the presence of an enzyme able to retroreduce the overoxidized form of Prxs. These results were further confirmed by studies of different mammalian 2-Cys Prxs (Chevallet et al., 2003), but the identification of the proposed enzyme was carried out by Biteau et al. (2003). They observed how yeast treated with $\mathrm{H}_{2} \mathrm{O}_{2}$ induced overexpression of a new protein that they called Srx. Concurrently, deletion of the Srx gene reduced the tolerance of yeast to $\mathrm{H}_{2} \mathrm{O}_{2}$. Since its discovery in yeast (Biteau et al., 2003; Vivancos et al., 2005), Srxs have been studied, in mammals (Chang et al., 2004; Woo et al., 2005; Jeong et al., 2006), plants (Liu et al., 2006; Rey et al., 2007; Iglesias-Baena et al., 2010) and cyanobacteria (Pascual et al., 2010; Boileau et al., 2011).

The almost concomitant discovery of Srxs (Biteau et al., 2003) together with other redox active protein family called sestrins, described in prokaryote and animal systems (Budanov et al., 2004), as novel enzymes able to regenerate the overoxidized forms of Prxs brought several implications. Firstly, a new enzyme was added to the redox network of Prx adding a new level of regulation. Secondly, the span life of Prxs in the cell increased as a direct implication of their regeneration by Srx and sestrins. Consequently, the concept of a constant rate for "de novo Prx synthesis" needs to be reevaluated. Regeneration of Prxs partially challenges the idea of overoxidized Prxs as cellular indicators of overoxidation: assuming that only the sulfinic form of Prx can be retroreduced, only the sulfonic overoxidized form could work as permanent cell markers as long as they last inside the cell and before being degraded by the cell scavengers. The controversial capability of sestrins to retroreduce overoxidized Prxs (Woo et al., 2009) has drastically diluted their impact in the redox literature, while Srxs have emerged as their clear regenerators, establishing the triade Trx-Prx-Srx.

Sulfiredoxin are a special type of ATP-dependent reductase containing a conserved C-terminal cysteine critical for their antioxidant function (Jönsson and Lowther, 2007). Originally, Srxs were thought to be exclusively involved in the reduction of the sulfinic form of typical 2-Cys Prxs (Woo et al., 2005). Subsequent studies carried out by Iglesias-Baena et al. (2011) demonstrated a 


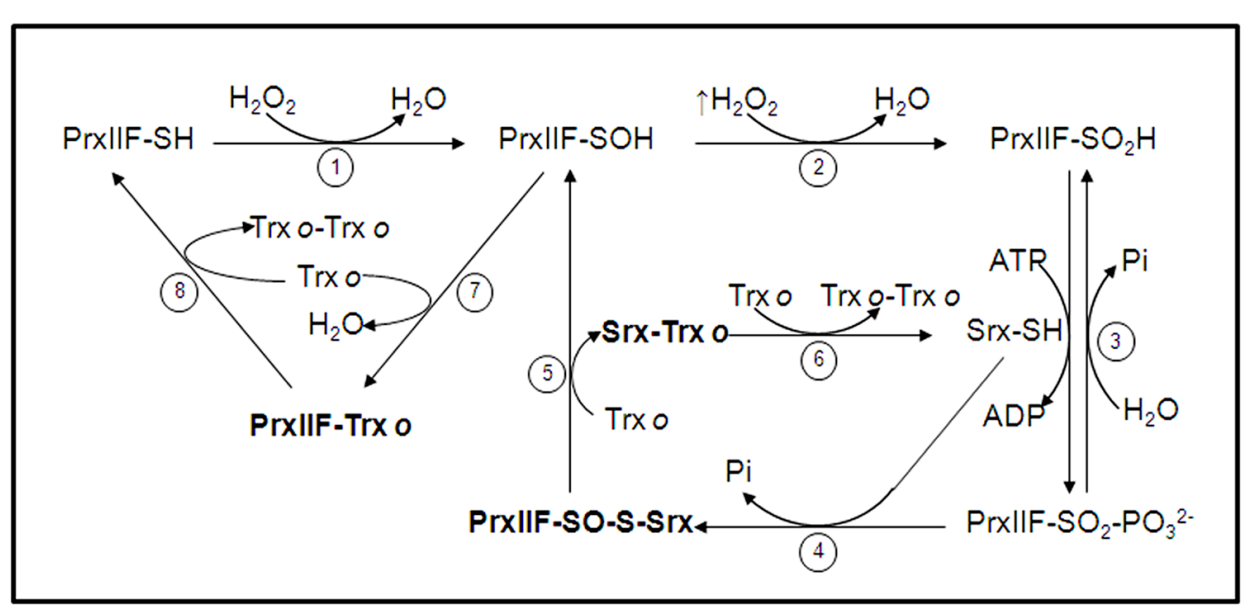

FIGURE 4 | Catalytic cycle of mitochondrial PrxIIF overoxidation and regeneration by Srx. In physiological conditions mitochondrial PrxIIF is oxidized to its sulfenic form in the reduction of peroxides (step 1). At high concentration of $\mathrm{H}_{2} \mathrm{O}_{2}$ PrxllF may be overoxidized to the inactive sulfinic form (PrxllF-SO $\mathrm{SO}_{2} \mathrm{H}$; step 2) that is phosphorilated, through a reversible step, in the presence of Srx and ATP (step 3). The phosphoril ester ( $\mathrm{PrxllF}-\mathrm{SO}_{2}-\mathrm{PO}_{3}^{2-}$ ) is converted into sulfinate (PrxllF-SO-S-Srx) with $\mathrm{Srx}$ and $\mathrm{Pi}$ is released (step 4). A reducing agent (mitochondrial Trxo) reduces the heterocomplex to release PrxIIF-SOH and Srx-Trxo (step 5). The complex Srx-Trxo is subsequently reduced to Srx-SH by Trxo (step 6). The sulfenic form of PrxllF is reduced by Trxo that forms the intermolecular complex PrxIIF-Trxo (step 7) and the active PrxIIF-SH is released by another Trxo (step 8) that forms the dimer Trxo-Trxo. The binary complexes between the three proteins in the cycle (sulfinic PrxllF, Srx and Trxo) are in bold type. (cif. ref. Iglesias-Baena etal., 2011). broader specificity toward the inactive sulfinic forms of atypical plant PrxIIF and atypical human PrxV. These encouraging results stimulate future investigations to establish a general mechanism of retroreduction for the broad diversity of plants Prxs, which could, presumably, respond to the Prx type as well as the subcellular localization. Although mammal Srx are cytosolic, the sulfinic form of mitochondrial human 2-Cys PrxIII can be reduced by hSrx (Woo et al., 2005). Recently, Noh et al. (2009) have reported the hSrx translocation from cytosol to mitochondria under oxidative stress to reduce overoxidized hPrxIII. These results reinforce the hypothesis of a general mechanism of Srx assisting in the regeneration of a broad battery of Prxs. However, the fine mechanism of chemiotaxis targeting Srx to different compartments as a response to the redox conditions needs to be addressed. An aggressive oxidative stress would lead to an increment in the protein concentration and detection in mitochondria. A different scenario have been reported in plants (pea and Arabidopsis) in which Srxs were found in chloroplasts and mitochondria regardless of the redox state (Liu et al., 2006; Rey et al., 2007; Iglesias-Baena et al., 2010, 2011). Additional works with Srxs and Prxs from different organisms are needed to tackle the ambiguous localization and substrate specificity of Srx.

The mitochondrial Srx retroreduces the inactive sulfinic form of atypical PrxIIF, employing a mechanism similar to that proposed for other Srxs (Jönsson et al., 2008). One oxygen atom on the sulphinic moiety of the oxidized PrxIIF functions as a nucleophile and attacks the $\gamma$-phosphate of ATP at the Srx to yield a sulphinic acid phosphoryl ester intermediate that is resolved by the nucleophilic attack of the Cys from the Srx (Figure 4). This mechanism involves two binary complexes, namely PrxIIFSrx and Srx-Trxo. Only the sulfinic form of PrxIIF interacts with Srx (Iglesias-Baena et al., 2011). A secondary complex Srx-Trx has been isolated through formation of a mixed disulfide between
Srx and C36STrx (Iglesias-Baena et al., 2011). Roussel et al. (2009) have also demonstrated that Trx forms an efficient complex with Srx. Both complexes, PrxIIF-Srx and Trx-Srx strengthen the proposed mechanism for sulfinic PrxIIF reduction by Srx.

Arabidopsis srx (AtSrx) gene codes for a protein bearing a transit peptide in the $\mathrm{N}$-terminus with the characteristics of dual import to chloroplast and mitochondria (Pujol et al., 2007; Mitschke et al., 2009; Iglesias-Baena et al., 2010, 2011). The mature Srx has a catalytic cysteine (Cys72) involved in the activity. Plant Srxs have an additional non-catalytic cysteine (Cys88; Iglesias-Baena et al., 2010) and, similar to mammalian Srxs, display low efficiency as retroreducing enzymes (Jönsson and Lowther, 2007). Unlike human Srx, only able to retroreduce typical 2-Cys-Prx, AtSrx has a lower substrate specificity showing activity toward typical and atypical Prxs, in different cellular compartments and in different organisms. The concentration of AtSrx was estimated as $0.2 \%$ of the total chloroplast protein (Iglesias-Baena et al., 2010, 2011).

Systematic site-directed mutagenesis and molecular modeling suggest that plant Srx has special characteristics that differentiate it from its counterparts in humans (Iglesias-Baena et al., 2010). Although this singularity of plant Srx does not change its reaction mechanism, the structural differences with mammalian Srx can be related with a broad specificity, including atypical Prxs.

\section{Trx/Prx/Srx SYSTEM IN STRESS RESPONSE AND SIGNALING}

The involvement of Trxs, Prxs and Srxs in plant tolerance to abiotic stress including salinity is not widely reported in the literature (Barranco-Medina et al., 2007; Pulido et al., 2009; Tripathi et al., 2009). The existing data have allowed the attribution to the Trx/Prx/Srx system of a redox sensing and signal transduction function (Rouhier and Jacquot, 2005) as well as its participation in the repair of oxidized proteins during environmental 
stress (Dos Santos and Rey, 2006). Leaf transcriptome results of salt-tolerant and salt-sensitive poplar, revealed that Trx members including chloroplast and cytosolic Trxs, displayed an inconsistent response to salt stress in the leaves, with the majority of the genes unchanged, whereas others showed up- or down-regulation under salinity conditions (Ding et al., 2010). Regarding mitochondrial Trxo1, an early induction in its gene expression at short salt treatments (five days at $150 \mathrm{mM} \mathrm{NaCl}$ ) was described in pea leaves, pointing to an adaptive behavior. Under long salt stress (15 days $150 \mathrm{mM} \mathrm{NaCl}$ ), a parallel increase in Trxol activity and protein levels were found with an unexpected down regulation of the gen (Martí etal., 2011). At this long stress, the induction of Trxol activity was correlated with the in vivo activity of the alternative pathway (AP) and with an increase in its capacity, reflecting the presence of the sustainable active form of AOX. PsTrxol could then have a role through the regeneration of oxidized AOX to the functional reduced enzyme. Under salt stress, increasing amounts and activity of Trxo1 might correlate also with either, the higher demand to regenerate the oxidized PrxIIF in mitochondria, or the interactions with other target proteins such as those of the photorespiration (Martí et al., 2011). More substantial biological information could be derived from the comparison between the overexpression of Trxol with its mammalian analog $\operatorname{Trx} 2$. Higher amounts of mitochondrial mammalian Trx-2, have been correlated with protection against $t$-butylhydroperoxide and etoposide-induced apoptosis (Chen et al., 2002) and cells deficient in Trx-2 had increased ROS production and exacerbated apoptosis (Tanaka et al., 2002).

Studies on the response of plant PrxIIF toward abiotic stress describe this mitochondrial antioxidant as a constitutive or responsive gen depending on the plant species and stress situation. No changes were described in PrxIIF mRNA levels in Arabidopsis leaves under $\mathrm{NaCl}, \mathrm{H}_{2} \mathrm{O}_{2}$, light or ozone treatments (Horling et al., 2002, 2003; Dietz et al., 2006). However, transcript and protein levels were up-regulated in Arabidopsis roots after cadmium treatment (Finkemeier et al., 2005), and in poplar leaves after exposure to chilling and water deficit (Gama et al., 2007). In pea plants exposed to salinity, cold and cadmium stress, an up-regulation in PrxIIF mRNA transcript and protein levels was reported in leaves, but not in roots (Barranco-Medina et al., 2007), and the most recent work on pea leaf PrxIIF regulation adds a new timedependent variable; PrxIIF presented a biphasic response toward salt stress increasing its transcript level after five days of treatment and decreasing after 14 days (Martí et al., 2011). Strikingly, PrxIIF protein content remained constant throughout the salt treatment but a PTM was detected at long time (see below; Camejo et al., 2013a).

Although PrxIIF is involved in acclimation under salinity stress, the enzyme is not essential for plant survival. Lack of PrxIIF in knock-out lines of Arabidopsis does not worsen the cellular redox state under optimal conditions and its absence might be compensated by increased mitochondrial APX activity (Finkemeier et al., 2005) or by the presence of the ASC-GSH cycle in mitochondria (Figure 5). Notwithstanding the compensatory mechanisms, significant changes in expression of both nuclear and mitochondrial genes were described in the mutants, suggesting that, together with its antioxidant function, PrxIIF is an important candidate for perception of changes in the redox-state in the mitochondria (Finkemeier et al., 2005).

Regulation of Srxs under abiotic stress is not conclusive yet, in part due to their recent discovery and the few works addressing this topic. In Arabidopsis, an induction of the chloroplast Srx transcript level has been reported in plants responding to cold treatment (Liu et al., 2006) as observed with mitochondrial PrxIIF (Barranco-Medina et al., 2007). In Arabidopsis, the absence of Srx in knock-out lines $(\triangle \mathrm{At} S r x)$ produced an accumulation, not only of the inactive chloroplastic sulfinic form of 2-Cys Prx, but also of the mitochondrial sulfinic PrxIIF, which is in accordance with its dual location. Besides, the deletion of Srx yielded into more sensitive $\Delta$ AtSrx plants against high concentration of $\mathrm{H}_{2} \mathrm{O}_{2}$ when compared with AtWT plants (Iglesias-Baena et al., 2010, 2011). Although Srx is not essential for plant viability, it protects chloroplast and mitochondria depending on the intensity of the oxidative stress to regenerate the inactive sulfinic Prxs (Figure 5; Vivancos et al., 2005).

The sulfinic PrxIIF lacking of peroxidase activity can exhibit signaling functions in the cell. Therefore, Srxs, by controlling the reversion of the sulfinic form of PrxIIF, could indirectly regulate the signaling process (Figure 5). Herein, we propose an integrative model of signaling/antioxidant function taking into account ROS and antioxidants. On allowing $\mathrm{H}_{2} \mathrm{O}_{2}$ to carry out its signaling function, its level must increase rapidly above a threshold (Rhee, 2006). To maintain this concentration, some antioxidant enzymes must remain inactive; among them, mAPX and sulfinic PrxIIF could help in this aim. When the fast signaling function of $\mathrm{H}_{2} \mathrm{O}_{2}$ has finished, the peroxidase activities of mAPX and PrxIIF can be recovered. Furthermore, high levels of ROS in the mitochondria can lead to PrxIIF overoxidation contributing to its oligomerization and a switch of activity from peroxidase to chaperone (Barranco-Medina et al., 2006). The link between activity and oligomerization is well correlated and seems to establish a general mechanism for Prxs (see the review by Barranco-Medina et al., 2009).

All the reported changes of the antioxidant and redox systems imply that stress tolerance seems to require the induction of specific isoforms in the different cell compartments or a constitutively higher content of antioxidants, depending on the species, variety or strength and duration of stress. In this context, mitochondrial Mn-SOD, APX, MDHAR, AOX, Trxol and PrxIIF appear as key enzymes in the ROS network, functioning in both, salt adaptation and signaling pathways (Figure 5).

The miss-correlation existing between gene expression, protein level and activity evidences a complex regulation in the response of plants to changing environments, and points out the relevance of post-transcriptional and PTMs in the tolerance mechanisms involving MRR.

\section{POST-TRANSLATIONAL MODIFICATIONS: THE IMPORTANT ROLE OF $S$-NITROSYLATION IN MITOCHONDRIAL PROCESSES \\ EFFECTS OF NO• AND ITS DERIVATES ON MITOCHONDRIA}

Mitochondria are exposed to $\mathrm{NO}^{\bullet}$ on activation of enzymatic emission associated to ETC and arginine or diffused from surrounding cell compartments (del Río et al., 2002; Blokhina and 


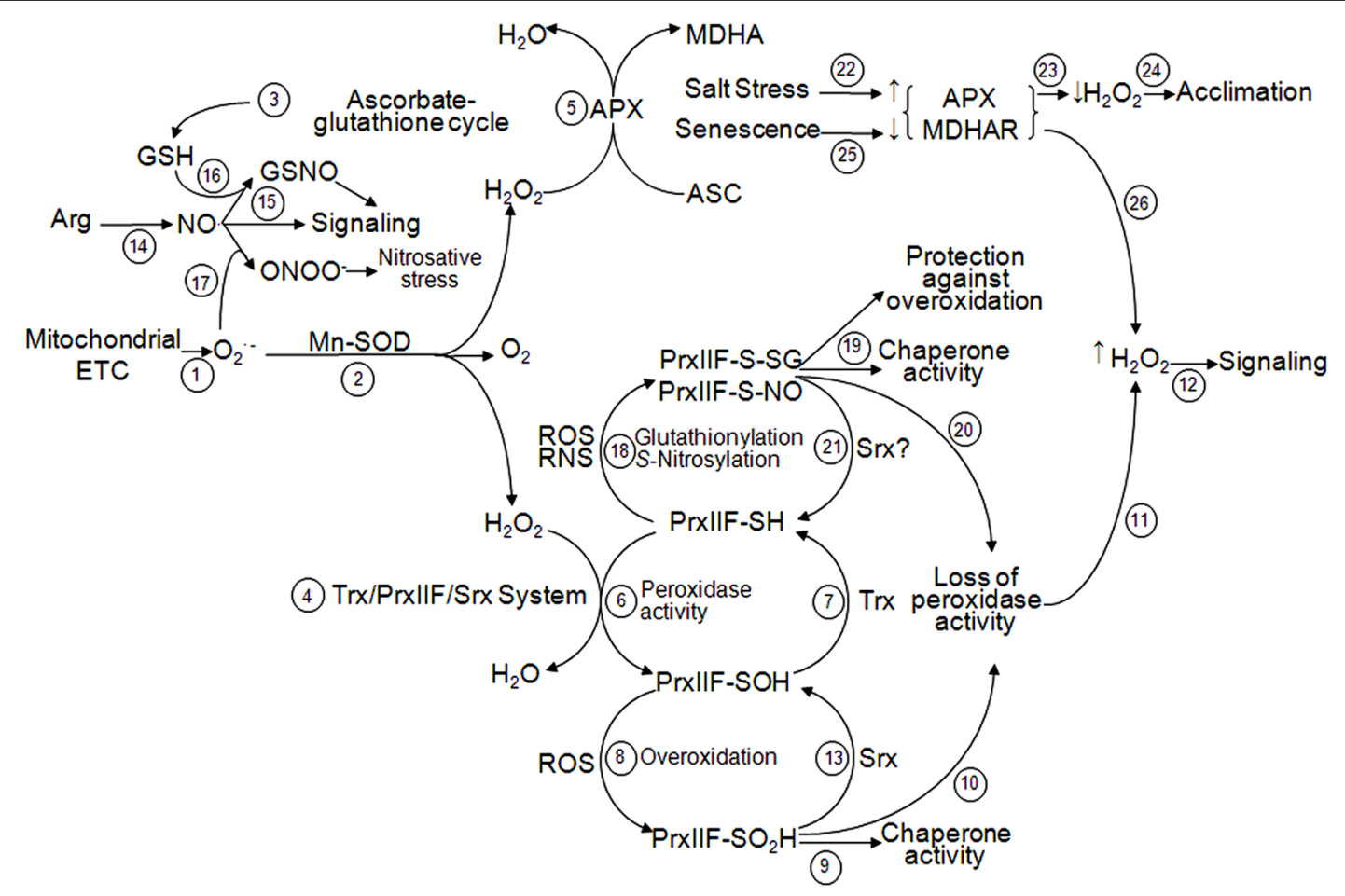

FIGURE 5 | Interaction between ascorbate-glutathione cycle and Trx/PrxIIF/Srx system in ROS and RNS signaling in plant mitochondria. Superoxide radicals $\left(\mathrm{O}_{2}^{\bullet-}\right)$ produced by the mitochondrial ETC (step 1) are dismutated to molecular $\mathrm{O}_{2}$ and $\mathrm{H}_{2} \mathrm{O}_{2}$ by the activity of Mn-SOD (step 2). $\mathrm{H}_{2} \mathrm{O}_{2}$ is reduced by two different systems: ascorbate-glutathione cycle (step 3) and Trx/PrxlIF/Srx system (step 4). In the ascorbate-glutathione cycle, $\mathrm{H}_{2} \mathrm{O}_{2}$ is reduced by APX (step 5) and throughout the cycle as indicated in Figure $\mathbf{1}$. In the $\mathrm{Tr} x / \mathrm{Prx}$ IIF/Srx system, $\mathrm{H}_{2} \mathrm{O}_{2}$ is reduced by the peroxidase activity of PrxIIF (step 6) that produces its sulfenic form (PrxIIF-SOH) and is reduced by the Trx system (step 7) as indicated in Figures 2 and $\mathbf{3}$. Under oxidative stress, PrxIIF-SOH can be overoxidized to the sulfinic form $\left(\mathrm{PrxlIF}_{-} \mathrm{SO}_{2} \mathrm{H}\right.$; step 8) that gains chaperone activity (step 9) losing its peroxidase activity (step 10). This loss of activity increase $\mathrm{H}_{2} \mathrm{O}_{2}$ concentration in the mitochondria (step 11) allowing the signaling (step 12). PrxIIF-SO $\mathrm{S}_{2} \mathrm{H}$ can be regenerated to the reduced form by the action of Srx (step 13) and Trx (step 7) as indicated in Figure 4. The generation of $\mathrm{NO}^{\bullet}$ in the mitochondria (step 14) allows signaling (step 15) in addition of forming GSNO by reduction with GSH from ascorbate-glutathione cycle (step 16). $\mathrm{NO}^{\bullet}$ can react with $\mathrm{O}_{2}^{\bullet-}$, produced by the mitochondrial ETC, to form $\mathrm{ONOO}^{-}$that bursts nitrosative stress (step 17). Under oxidative or nitrosative stress, PrxIIF-SH can be glutationylated or $S$-nitrosylated (step 18) in order to protect the enzyme against overoxidation and to gain chaperone activity (step 19). PrxIIF-S-SG and PrxIIF-S-SNO lose the peroxidase activity (step 20), allowing the signaling by $\mathrm{H}_{2} \mathrm{O}_{2}$ (step 11 and 12). These post-translational modifications could be reverted to PrxIIF-SH by the Srx activity (step 21) as it happens with the 2-Cys Prx. On the other hand, salt stress induces an increase of APX and MDHAR (step 22), which produces a decrease in the concentration of $\mathrm{H}_{2} \mathrm{O}_{2}$ (step 23) allowing acclimation (step 24). During the oxidative mechanism of senescence there are decreases of APX and MDHAR activities (step 25) which produce an increase in $\mathrm{H}_{2} \mathrm{O}_{2}$ (step 26) allowing signaling (step 12).
Fagerstedt, 2010). $\mathrm{NO}^{\bullet}$ can affect mitochondrial metabolism involving oxidation of metals in proteins complexes and reduction of free metal ions. $\mathrm{NO}^{\bullet}$ can also react with oxygen to form oxidized $\mathrm{NO}^{\bullet}$, which interacts with mitochondrial GSH to form $S$-nitrosoglutahione (GSNO; Figure 5) or with thiol-containing molecules to yield low molecular weight $S$-nitrosocysteine and $S$ nitrosocystein glicyne in a process called $S$-nitrosylation (Hess and Stamler, 2012). GSNO is considered to be the most abundant lowmolecular mass $S$-nitrosothiol (SNO) and also a vehicle of $\mathrm{NO}^{\bullet}$ throughout the cell, which enables $\mathrm{NO}^{\bullet}$ activity to expand. GSNO has been located in pea mitochondria, together with cytosol, peroxisomes and chloroplasts (Corpas et al., 2013).

Prime targets of $\mathrm{NO}^{\bullet}$ and its derivates in plants, are the mitochondrial electron transport components and enzymes, producing an inhibition of cytochrome c pathway whereas alternative respiration via AOX is only partially inhibited (Day et al., 1996; Martí et al., 2012). These inhibitions may potentially be involved in the regulation of energy metabolism, generation of ROS, cell death and response to stress. From a pharmacological approach, mitochondrial Mn-SOD has been found to be not inactivated by $\mathrm{NO}^{\bullet}$ (Martí et al., 2012), although this enzyme binds and stimulates $\mathrm{NO}^{\bullet}$ decay under both anaerobic and aerobic conditions (Filipovic et al., 2007). However, $\mathrm{O}_{2}^{\bullet-}$ can react with $\mathrm{NO}^{\bullet}$ three times faster than with mitochondrial Mn-SOD (Yamakura et al., 1998), so generating $\mathrm{ONOO}^{-}$(Figure 5; Wilson et al., 2008), which represents a mechanism for $\mathrm{NO}^{\bullet}$ consumption by mitochondria. Thus, when mitochondria respiration is inhibited by $\mathrm{NO}^{\bullet}$, the formation of peroxynitrite contributes to $\mathrm{NO}^{\bullet}$ degradation, reactivation of COX and restoration of oxygen consumption (Poderoso et al., 1996). The observed insensitivity of AOX to NO•also represents another mechanism to prevent its deleterious effects on respiratory activity (Millar and Day, 1996; Martí etal., 2012). Recent results highlight the importance of AOX in the control of $\mathrm{NO}^{\bullet}$ level in plants; mitochondrial $\mathrm{NO}^{\bullet}$ content is increased in the absence of AOX (Cvetkovska and Vanlerberghe, 2012), and curiously a NO-dependent up-regulation of $A O X$ gene has been 
described (Huang et al., 2002). Furthermore the mitochondrial heme-enzyme APX (mAPX) was found to be reversibly inhibited by $\mathrm{NO}^{\bullet}$ in an ascorbate dependent manner, which could have physiological relevance during oxidative and/or nitrosative stress conditions where ASC depletion may occur (de Pinto et al., 2006; Martí et al., 2012). Hence, mAPX could be part of a NO ${ }^{\bullet}$ redox signaling pathway in mitochondria, through the $\mathrm{H}_{2} \mathrm{O}_{2}$ and $\mathrm{NO}^{\bullet}$ signaling cross-talk (Bright et al., 2006). Like Mn-SOD, mitochondrial MDHAR, DHAR and GR enzymes were not inhibited under continuous fluxes of $\mathrm{NO}^{\bullet}$, which may contribute significantly to prevent a build-up of ROS, and also to allow the recycling of ASC and GSH from its oxidized forms, thus reducing the risk of RNS accumulation (Martí et al., 2012).

Overall the results probably indicate that not only $\mathrm{NO}^{\bullet}$ resistant AOX but also mAPX, may be important components of the $\mathrm{H}_{2} \mathrm{O}_{2}$-signaling pathways under conditions inducing the production of NO in this organelle (Martí et al., 2012). New studies are needed to further elucidate the physiological relevance of the relation between mitochondrial $\mathrm{NO}^{\bullet}$ and derivates, and the ASC-GSH cycle enzymes under normal and stressful conditions.

\section{MITOCHONDRIAL TARGETS OF $S$-NITROSYLATION}

Cellular functions of $\mathrm{NO}^{\bullet}$ are carried out in part through $S$ nitrosylation, a dinamic PTM for the regulation of the protein function (Hess et al., 2005). Several mechanisms of S-nitrosylation have been proposed, but those operating in plant cells have not yet been elucidated (Kovacs and Lindermayr, 2013). Biological $S$-nitrosylation can take place by transnitrosylation, which involves the transfer of $\mathrm{NO}^{\bullet}$ onto a cysteine thiol. Recent findings underscore the importance of subcellular compartimentation in determining when and where proteins are $S$-nitrosylated during signal transduction. In recent years, a long list of plant proteins undergoing $S$-nitrosylation and cellular processes affected has been identified from proteome-wide analysis by using $\mathrm{NO}^{\bullet}$ donors as $S$-nitrosylating agents or by biotic and abiotic stressors, in cultured cells, whole leaves and cellular organelles (Lindermayr et al., 2005; Romero-Puertas et al., 2008; Astier et al., 2011; Fares et al., 2011). Thus, more than 50 S-nitrosylated candidate proteins were identified in Arabidopsis leaves, including cytosolic PrxIIB, chloroplast Trxf1 and a chloroplast PrxIIE, among others (Lindermayr et al., 2005). S-nitrosylation in PrxIIE was demonstrated to inhibit its peroxidase and peroxynitrite reductase activity. Authors suggested a model where this PTM regulates the transduction of $\mathrm{NO}^{\bullet}$ and ROS-linked signals during infection by $P$. syringae, highlighting a key role for PrxIIE in controlling the endogenous level of $\mathrm{ONOO}^{-}$(Romero-Puertas et al., 2007, 2008). Recent studies have demonstrated that the Trx system may be involved in regulating the $S$-nitrosylation status of target proteins in different systems (Wu et al., 2011) through the transnitrosylation or denitrosylation, thus modulating their biological activities (Benhar et al., 2008; Kornberg et al., 2010). In mammalian systems, a subpopulation of caspase- 3 in the mitochondria is constitutively $S$-nitrosylated and, as such, is inhibited, and mitochondrial Trx2 has been involved in this $S$-nitrosylation (Mitchell and Marletta, 2005), although the exact intramolecular mechanism of Trx denitrosylation remains ill-defined, as does the denitrosylation target specificity (Benhar et al., 2009). To the date, no information on the putative S-nitrosylation capacity for plant mitochondrial Trxo1 and its transnitrosylating/denitrosylating activity is available. In addition to Trx, S-nitrosoglutathione reductase (GSNOR) plays a predominant role in protein denitrosylation (Benhar et al., 2009). In mitochondria from Arabidopsis plants treated with GSNO, 11 proteins were identified as possible targets for $S$-nitrosylation (Lindermayr et al., 2005). Some of these proteins were mETC constituents and three of them were subunits of the glycine decarboxylase complex (GDC H1, T and P proteins), a key enzyme of the photorespiratory $\mathrm{C} 2$ cycle. The activity of this enzyme complex was inhibited by $S$-nitrosylation, and appears to be involved in the regulation of $\mathrm{NO}^{\bullet}$ dependent signal transduction, although the underlying signaling pathway remains elusive (Palmieri et al., 2010).

It has been shown that AOX is co-expressed with GDC and the decrease of GDC amount in mitochondria also results in very low AOX levels (Bykova et al., 2005). GSNO treatment also inhibits complex I, and as a result, increases ROS in mitochondria, which could later affect chloroplastic ROS through reduced photorespiratory capacity (Gupta, 2011). Endogenous S-nitrosylation protein pattern in mitochondria from Pisum sativum leaves was reported as being similar or even higher than that found for mitochondrial proteins in other sources, including Arabidopsis (Tanou et al., 2009; Fares etal., 2011). A differential pattern of target proteins was identified during plant development, with a minor number of $S$-nitrosylated proteins in older plants, specifically some key enzymes related with respiration and photorespiration, including GDC T and GDC P subunits, NAD-MDH, succinate dehydrogenase, NADH ubiquinone oxidoreductase and ADP/ATP carrier, which disappeared as $S$-nitrosylated targets, while elongation factor $\mathrm{Tu}$ and protein kinase appeared as new targets of $S$-nitrosylation. Similar to GDC, $S$-nitrosylation of peroxisomal isozyme NAD-MDH also decreased its activity (Ortega-Galisteo et al., 2012). The differential S-nitrosylation pattern during development may be a mechanism for avoiding malfunction of the photorespiratory cycle and that of the respiratory components, which can further increase mitochondrial and chloroplastic ROS levels and affect redox signaling during this process (Camejo etal., 2013a). To date, the significance of the regulation of both processes by $S$-nitrosylation/denitrosylation during plant development remains undefined.

\section{$S$-NITROSYLATION UNDER SALT STRESS}

The participation of $\mathrm{NO}^{\bullet}$ in plants in response to biotic and abiotic stress including drought and salt stress has been demonstrated. The real role of $\mathrm{NO}^{\bullet}$ in the cell is not exempt of controversy. While some authors consider $\mathrm{NO}^{\bullet}$ as a stress-inducing agent, others have reported its protective task (Huang et al., 2002; Neill et al., 2003; del Río et al., 2004; Leitner et al., 2009; Rodríguez-Serrano et al., 2009). $\mathrm{NO}^{\bullet}$ was recently proposed in the mediation of the response to salinity in different plant systems and varieties (Gould et al., 2003), not only for its harmful reactivity and toxicity but also for its involvement as signal molecule able to mitigate the damage associated with salt stress, either in plants and germinating seeds (Zheng et al., 2009). In pea plants, the increase observed in $\mathrm{NO}^{\bullet}$ content by long-term salt treatments (14 days) was, in part, associated to mitochondria, although the contribution of 
other organelles, like peroxisomes and cytosol was not discarded (Rodríguez-Serrano et al., 2009; Camejo et al., 2013a).

In salt-stressed plants, the information for $S$-nitrosylation in mitochondria is quite limited, despite the significant developments in proteomics analysis allowing the identification of mitochondrial proteins suffering changes in abundance under salinity (Taylor et al., 2009; Jacoby et al., 2010). Recently 49 proteins including mitochondrial enzymes were identified as targets of $S$-nitrosylation in response to $\mathrm{NaCl}$-stress in citrus plants (Tanou et al., 2009). In pea leaf mitochondria, at least 9 S-nitrosylated proteins were described under salt-stress, but as reported during pea development, as the stress became longer, so the number of identified protein targets decreased. This affected some enzymes related to $\mathrm{NADH}$ metabolism, as $\mathrm{MDH}$, the photorespiratory GDC P and T subunit, and also Mn-SOD and aminomethyltransferase, identified as $S$-nitrosylated at short salinity period (5 days). Interestingly, mitochondrial PrxIIF and a heat shock Hsp90 protein appeared as new $S$-nitrosylation targets during the salt stress progression. Others enzymes involved in respiration were Succinate dehydrogenase, NADH ubiquinone oxidoreductase, and in photorespiration SHMT were found S-nitrosylated in control pea mitochondria but not under salt-stress. Thus, the denitrosylation of the respiratory activities may not limit ETC transport, at least through the AP which was not decreased with salt stress, as previously reported (Martí et al., 2011). The denitrosylation of the three key enzymes of photorespiration, was not accompanied by changes in its protein content and may allow this process to be functional after long period of salt stress. All these changes may contribute to the elevated $\mathrm{NADH} / \mathrm{NAD}^{+}$and the maintained $\mathrm{NAD}(\mathrm{P}) \mathrm{H} / \mathrm{NADP}^{+}$produced in pea mitochondria inducing a modification in the mitochondrial matrix or ETC redox state. Several mitochondrial dehydrogenases are described to be affected by changes in the NADH/NAD ${ }^{+}$ ratio depending on their kinetics characteristics (Noctor et al., 2007). Another possible destination for reducing equivalents in mitochondria is the Trx system. In pea plants, the expression, content and activity of Trxol were increased under salt stress (Martí et al., 2011), so Trxol could play a pivotal role in sensing the local redox environment and regulating the activity of its target enzymes through reduction of their disulfide bridges. Consequently, functional photorespiration can prevent important photooxidative damage as results of the more intense salt-induced reduction of stomatal conductance at long-term salt stress (Martí etal., 2012). A functional role for the cooperation between the mitochondria, chloroplast and peroxisomes to modulate cell redox homeostasis under salinity and drought stress has been described (Noctor etal., 2007; Pastore etal., 2007).

The increase in $\mathrm{NO}^{\bullet}$ content under salt conditions was not related to an enhanced mitochondrial protein $S$-nitrosylation (Camejo et al., 2013a), raising the question of whether $\mathrm{NO}^{\bullet}$ could exhibit different actions. GSNOR activity was also induced under salt conditions and might constitute a mechanism of the degradation of SNOs, so influencing $\mathrm{NO}^{\bullet}$ level in mitochondria by preventing $\mathrm{NO}^{\bullet}$ kidnapping.

As a new target of $S$-nitrosylation under short salt stress, $\mathrm{Mn}$ SOD does not seem to be affected in its activity, either under salt conditions or after GSNO treatment of mitochondria (Martí et al., 2012; Camejo et al., 2013a). These results corroborated the previously reported antioxidant function of this important enzyme under salt stress, as a ROS scavengers and possible NO ${ }^{\bullet}$ sink (Hernández et al., 2000; Wang et al., 2004; Jacoby et al., 2010). Only during long-term salt stress, PrxIIF was found as $S$-nitrosylated (Figure 5) parallel to an increase of $\mathrm{NO}^{\bullet}$, while the protein amount did not change. S-nitrosylation of PrxIIF was not previously described, although a strong posttranslational regulation to explain its response to high $\mathrm{H}_{2} \mathrm{O}_{2}$ concentration was suggested (Finkemeier et al., 2005). This modification may inhibit its peroxidase activity during salt stress, as indicated after treatment of the recombinant pea PrxIIF with GSNO (Camejo et al., 2013a). This inhibition suggests a role for PrxIIF as a signaling component more than as an antioxidative enzyme during long $\mathrm{NaCl}$ stress (Figure 5). Recently, a change in PrxIIF peroxidase activity to chaperone by in vitro $S$-nitrosylation of recombinant protein has been observed (Camejo et al., 2013b). It could be important to address whether this process is also taking place and to what intensity, under salt stress, when endogenous PsPrxIIF appears as $S$-nitrosylated.

\section{CONCLUSIONS AND PERSPECTIVES}

Redox regulation and ROS metabolism are interlinked and involved in optimizing the function of cell organelles. The mitochondrial antioxidant system has a key role in the detoxification of $\mathrm{O}_{2}^{\bullet-}$ and peroxides and thus plays a crucial role in controlling redox signaling. Redox proteome and in vitro recombinant protein studies have shown that many of the mitochondrial proteins undergo different redox PTMS, so modulating their antioxidant activity. A good example is Prx, including mitochondrial PrxIIF and Prx 3 in plants and mammalian, respectively. Thus, PrxIIF can be partially inactivated by hyperoxidation, glutathionylation and $S$-nitrosylation or by the extent of its oligomerization. To relate these modifications to events in situ it is important to distinguish between protective and signaling purposes under physiological and abiotic stress responses. Also, to understand how these redox PTMs regulate mitochondrial redox signaling it would be necessary to know how the different types of PTMs are coordinated and/or interconnected to allowing specific proteins to respond not only to different stimuli, but also to their intensity and duration.

Many thiols in proteins are susceptible to redox modifications, but only a few are important in signaling pathways. Some studies also highlight the concept that some protein cysteine residues are differently susceptible to NO-modifications and the functionality of reactive Cys as NO-sensor "in vivo" and their regulation by NO affecting biological processes is still little known. The study of these aspects would help to clarify the true significance of redox signaling.

Post-translational modifications on plant mitochondrial ASCGSH cycle enzymes have not yet been studied in detail and although the reversible inhibition of APX by NO and its irreversible inactivation by $\mathrm{ONOO}^{-}$have been reported, there is scarce information about the "in vivo" NO's effects on these antioxidant enzymes. The link between $\mathrm{NO}^{\bullet}$ and the ASC-GSH cycle enzymes is an essential target to clarify $\mathrm{NO}^{\bullet}$ participation in redox signaling that awaits further functional characterization. 
Similarly, the redox state of the Trxol can reversibly affect the activity of target proteins. Moreover, given that some Trxs can reduce sulfenic acids, SNOs and glutathionylated cysteines and could promote trans-nitrosylation reactions, the putative involvement of Trxol in some of these reactions should be analyzed in future studies. Additionally, the mechanism of protein deglutathionylation catalyzed by Srx still needs to be explored as well as its functional significance.

Thus, another interesting question will be to assess the functional aspect of AOX redox regulation by Trxo1 in controlling mitochondrial $\mathrm{NO}^{\bullet}$ levels. This aspect may help to reinforce the model of cross-talk between NO/ROS in mitochondria. It would be also advisable to study the putative interaction between mAPX and Trxol for a better understanding of the mitochondrial response to oxidative stress.

Finally, an understanding of the above proposed aspects of the cross-talk between signaling pathways linked to ROS and RNS is also a major issue to elucidate the mechanisms underlining plant abiotic stress tolerance.

\section{ACKNOWLEDGMENTS}

The authors would like to thank the support of Daymi Camejo by JAE-CSIC Research program and María del Carmen Martí by the Séneca Foundation. This work was supported by MICINN (BFU2011-28716, BIO2008-04067) and Séneca Foundation, Murcia, Spain (04553/GERM/06). The authors apologize to the scientists that are not cited because of space limitation and thank Dr. Stephen Hasler for correction of the written English in the manuscript.

\section{REFERENCES}

Anedda, A., López-Bernardo, E., Acosta-Iborra, B., Suleiman, M. S., Landázuri, M. O., and Cadenas, S. (2013). The transcription factor Nrf2 promotes survival by enhancing the expression of uncoupling protein 3 under conditions of oxidative stress. Free Radic. Biol. Med. 61, 395-407. doi: 10.1016/j.freeradbiomed.2013.04.007

Aono, M., Kubo, A., Saji, H., Tanaka, K., and Kondo, N. (1993). Enhanced tolerance to photooxidative stress of transgenic Nicotiana tabacum with high chloroplastic glutathione reductase activity. Plant Cell Physiol. 34, 129-135.

Arrigoni, O., Dipierro, S., and Borranccino, G. (1981). Ascorbate free radical reductase: a key enzyme of the ascorbic acid system. FEBS Lett. 125, 242-244. doi 10.1016/0014-5793(81)80729-6

Ashraf, M. (2009). Biotechnological approach of improving plant salt tolerance using antioxidants as markers. Biotech. Adv. 27, 84-93. doi: 10.1016/j.biotechadv.2008.09.003

Astier, J., Rasul, S., Koen, E., Manzoor, H., Besson-Bard, A., Lamotte, O. et al. (2011). S-nitrosylation: an emerging post-translational protein modification in plants. Plant Sci. 181, 527-533. doi: 10.1016/j.plantsci.2011. 02.011

Attia, H., Arnaud, N., Karray, N., and Lachaâl, M. (2008). Long-term effects of mild salt stress on growth, ion accumulation and superoxide dismutase expression on Arabidopsis rosette leaves. Physiol. Plant. 132, 293-305. doi: 10.1111/j.13993054.2007.01009.x

Badawi, G. H., Yamauchi, Y., Shimada, E., Sasaki, R., Kawano, N., Tanaka, K., et al. (2004). Enhanced tolerance to salt stress and water deficit by overexpressing superoxide dismutase in tobacco (Nicotiana tabacum) chloroplasts. Plant Sci. 166, 919-928. doi: 10.1016/j.plantsci.2003.12.007

Baier, M., and Dietz, K. J. (1996). Primary structure and expression of plant homologues of animal and fungal thioredoxin-dependent peroxide reductases and bacterial alkyl hydroperoxide reductases. Plant Mol. Biol. 31, 553-564. doi: 10.1007/BF00042228
Balmer, Y., Vensel, W. H., Tanaka, C. K., Hurkman, W. J., Gelhaye, E., Rouhier, N., et al. (2004). Thioredoxin links redox to the regulation of fundamental processes of plant mitochondria. Proc. Natl. Acad. Sci. U.S.A. 101, 2642-2647. doi: 10.1073/pnas.0308583101

Barranco-Medina, S., Kakorin, S., Lázaro, J. J., and Dietz, K. J. (2008a). Thermodynamics of the dimmer-decamer transition of reduced human and plant 2-Cys peroxiredoxin. Biochemistry 47, 7196-7204. doi: 10.1021/bi8 002956

Barranco-Medina, S., Krell, T., Bernier-Villamor, L., Sevilla, F., Lázaro, J. J., and Dietz, K. J. (2008b). Hexameric oligomerization of mitochondrial peroxiredoxin PrxIIF and formation of an ultrahigh affinity complex with its electron donor thioredoxin Trx-o. J. Exp. Bot. 59, 3259-3269. doi: 10.1093/jxb/ern177

Barranco-Medina, S., Krell, T., Finkemeier, I., Sevilla, F., Lazaro, J. J., and Dietz, K. J. (2007). Biochemical and molecular characterization of the mitochondrial peroxiredoxin PsPrxII F from Pisum sativum. Plant Physiol. Biochem. 45, 729-739. doi: 10.1016/j.plaphy.2007.07.017

Barranco-Medina, S., Lázaro, J. J., and Dietz, K. J. (2009). The oligomeric conformation of peroxiredoxins links redox state to function. FEBS Lett. 583, 1809-1816. doi: 10.1016/j.febslet.2009.05.029

Barranco-Medina, S., López-Jaramillo, F. J., Bernier-Villamor, L., Sevilla, F., and Lázaro, J. J. (2006). Cloning, overexpression, purification and preliminary crystallographic studies of a mitochondrial type II peroxiredoxin from Pisum sativum. Acta Crystallogr. Sect. F Struct. Biol. Cryst. Commun. 62, 696-698. doi: 10.1107/S1744309106023451

Bartoli, C. G., Pastori, G. M., and Foyer, C. H. (2000). Ascorbate biosynthesis in mitochondria is linked to the electron transport chain between complexes III and IV. Plant Physiol. 123, 335-344. doi: 10.1104/pp.123. 1.335

Beer, S. M., Taylor, E. R., Brown, S. E., Dahm, C. C., Costa, N. J., Runswick, M. J., et al. (2004). Glutaredoxin 2 catalyzes the reversible oxidation and glutathionylation of mitochondrial membrane thiol proteins: implications for mitochondrial redox regulation and antioxidant defense. J. Biol. Chem. 279, 47939-47951. doi: 10.1074/jbc.M408011200

Benhar, M., Forrester, M. T., Hess, D. T., and Stamler, J. S. (2008). Regulated protein denitrosylation by cytosolic and mitochondrial thioredoxins. Science 320, 1050-1054.1158265

Benhar, M., Forrester, M. T., and Stamler, J. S. (2009). Protein denitrosylation: enzymatic mechanisms and cellular functions. Nat. Rev. Mol. Cell Biol. 10, 721732. doi: 10.1038/nrm2764. Epub 2009 Sep 9

Bernier-Villamor, L., Navarro, E., Sevilla, F., and Lázaro, J. J. (2004). Cloning and characterization of a 2-Cys peroxiredoxin from Pisum sativum. J. Exp. Bot. 55, 2191-2199. doi: 10.1093/jxb/erh238

Biteau, B., Labarre, J., and Toledano, M. B. (2003). ATP-dependent reduction of cysteine-sulphinic acid by S. cerevisiae sulphiredoxin. Nature 425, 980-984. doi: 10.1038 /nature02075

Blokhina, O., and Fagerstedt, K. V. (2010). Reactive oxygen species and nitric oxide in plant mitochondria: origin and redundant regulatory systems. Physiol. Plant. 138, 447-462. doi: 10.1111/j.1399-3054.2009. 01340.x

Boileau, C., Emele, L., Brochier-Armanet, C., Janicki, A., Zhang, C. C., and Lafiti, A. (2011). A eukaryotic-like sulfiredoxin involved in oxidative stress responses and in the reduction of the sulfinic form of 2-Cys peroxiredoxin in the cyanobacterium Anabaena PCC 7120. New Phytol. 191, 1108-1118. doi: 10.1111/j.1469-8137.2011.03774.x

Bonifacio, A., Martins, M. O., Ribeiro, C. W., Fontenele, A. V., Carvalho, F. E., Margis-Pinheiro, M., et al. (2011). Role of peroxidases in the compensation of cytosolic ascorbate peroxidase knockdown in rice plants under abiotic stress. Plant Cell Environ. 34, 1705-1722. doi: 10.1111/j.1365-3040.2011.02366.x

Bright, J., Desikan, R., Hancock, J. T., Weir, I. S., and Neill, S. J. (2006). ABAinduced NO generation and stomatal closure in Arabidopsis are dependent on H2O2 synthesis. Plant J. 45, 113-122. doi: 10.1111/j.1365-313X.2005.02615.x

Budanov, A. V., Sablina, A. A., Feinstein, E., Koonin, E., V., and Chumacov, P. M. (2004). Regeneration of peroxiredoxins by p53-regulated sestrins, homologs of bacterial AhpD. Science 304, 596-600. doi: 10.1126/science. 1095569

Burke-Gaffney, A., Callister, M. E. J., and Nakamura, H. (2005). Thioredoxin: friend or foe in human disease? Trends Pharmacol. Sci. 26, 398-404. doi: 10.1016/j.tips.2005.06.005 
Bykova, N. V., Keerberg, O., Pärnik, T., Bauwe, H., and Gardeström, P. (2005). Interaction between photorespiration and respiration in transgenic potato plants with antisense reduction in glycine decarboxylase. Planta 222, 130-140. doi: 10.1007/s00425-005-1505-9

Camejo, D., Romero-Puertas, M. C., Rodríguez-Serrano, M., Sandalio, L. M., Lázaro, J. J., Jiménez, A., et al. (2013a). Salinity-induced changes in S-nitrosylation of pea mitochondrial proteins. J. Proteomics 79, 87-99. doi: 10.1016/j.jprot.2012.12.003

Camejo, D., Lázaro, J. J., Romero-Puertas, M. C., Lázaro-Payo, A., Sevilla, F., and Jiménez, A. (2013b). "S-nitrosylation promotes functional and structural changes in the mitochondrial PsPrxII F protein," in Proceedings of the 11th International POG Conference, Varsow.

Chae, H. Z., Robinson, K., Poole, L. B., Church, G., Storz, G., and Rhee, S. G. (1994). Cloning and sequencing of thiol-specific antioxidant from mammalian brain: alkyl hydroperoxide reductase and thiol-specific antioxidant define a large family of antioxidant enzymes. Proc. Natl. Acad. Sci. U.S.A. 91, 7017-7021. doi: 10.1073/pnas.91.15.7017

Chang, T. S., Jeong, W., Wooh, H. A., Lee, S. M., Park, S., and Rhee, S. G. (2004) Characterization of mammalian sulfiredoxin and its reactivation of hyperoxidized peroxiredoxin through reduction of cysteine sulfinic acid in the active site to cysteine. J. Biol. Chem. 279, 50994-51001. doi: 10.1074/jbc.M409482200

Chen, Y., Cai, J., Murphy, T. J., and Jones, D. P. (2002). Overexpressed human mitochondrial thioredoxin confers resistance to oxidant-induced apoptosis in human osteosarcoma cells. J. Biol. Chem. 277, 33242-33248. doi 10.1074/jbc.M202026200

Chevallet, M., Wagner, E., Luche, S., van Dorsselaer, A., Leize-Wagner, E., and Rabilloud, T. (2003). Regeneration of peroxiredoxins during recovery after oxidative stress. J. Biol. Chem. 278, 37146-37153. doi: 10.1074/jbc.M305161200

Chew, O., Whelan, J., and Millar, A. H. (2003). Molecular definition of the ascorbate-glutathione cycle in Arabidopsis mitochondria reveals dual targeting of antioxidant defenses in plants. J. Biol. Chem. 278, 46869-46877. doi 10.1074/jbc.M307525200

Clifton, R., Millar, A. H., and Whelan, J. (2006). Alternative oxidases in Arabidopsis a comparative analysis of differential expression in the gene family provides new insights into function of nonphosphorylating bypasses. Biochim. Biophys. Acto 1757, 730-741. doi: 10.1016/j.bbabio.2006.03.009

Collin, V., Lamkemeyer, P., Miginiac-Maslow, M., Hirasawa, M., Knaff, D. B., Dietz, K. J., etal. (2004). Characterization of plastidial thioredoxins from Arabidopsis belonging to the new y-type. Plant Physiol. 136, 4088-4095. doi: 10.1104/pp.104.052233

Collins, Y., Chouchani, E. T., James, A. M., Menger, K. E., Cochemé, H. M., and Murphy, M. P. (2012). Mitochondrial redox signaling at a glance. J. Cell Sci. 125 801-806. doi: 10.1242/jcs.098475

Corpas, F. J., Alché, J. D., and Barroso, J. B. (2013). Current overview of S-nitrosoglutathione (GSNO) in higher plants. Front. Plant Sci. 4:126. doi:10.3389/fpls.2013.00126. doi: 10.3389/fpls.2013.00126

Corpas, F. J., Palma, J. M., and del Río, L. A. (1993). Evidence for the presence of proteolytic activity in peroxisomes. Eur. J. Cell Biol. 61, 81-85.

Creissen, G. P., Broadbent, P., Kular, B., Reynolds, H., Wellburn, A. R., and Mullineaux, P. M. (1994). Manipulation of glutathione reductase in transgenic plants: implications for plants' responses to environmental stress. Proc. R. Soc Edinb. Biol. Sci. 102, 167-175. doi: 10.1017/S0269727000014081

Creissen, G. P., Reynolds, H., Xue, Y., and Mullineaux, P. (1995). Simultaneous targeting of pea glutathione reductase and of a bacterial fusion protein to chloroplasts and mitochondria in transgenic tobacco. Plant J. 8, 167-175. doi: 10.1046/j.1365-313X.1995.08020167.x

Cvetkovska, M., and Vanlerberghe, G. C. (2012). Alternative oxidase modulates leaf mitochondrial concentrations of superoxide and nitric oxide. New Phytol. 195 32-39. doi: 10.1111/j.1469-8137.2012.04166.x

Dai, Q., Chen, C., Feng, B., Liu, T. T., Tian, X., Gong, Y. Y., et al. (2009). Effects of different $\mathrm{NaCl}$ concentration on the antioxidant enzymes in oilseed rape (Brassica napus L.) seedlings. Plant Growth Regul. 59, 273-278. doi: 10.1007/s10725-0099402-Z

Dat, J., Vandenabeele, S., Vranová, E., Van Montagu, M., Inzé, D., and Van Breusegem, F. (2000). Dual action of the active oxygen species during plant stress responses. Cell. Mol. Life Sci. 57, 779-795. doi: 10.1007/s000180050041

Day, D. A., Krab, K., Lambers, H., Moore, A. L., Siedow, J. N., Wagner, A. M., et al. (1996). The cyanide-resistant oxidase: to inhibit or not to inhibit, that is the question. Plant Physiol. 110, 1-2. doi: 10.1104/pp.110.1.1 del Río, L. A., Corpas, F. J., and Barroso, J. B. (2004). Nitric oxide and nitric oxide synthase activity in plants. Phytochemistry 65, 783-792. doi: 10.1016/j.phytochem.2004.02.001

del Río, L. A., Corpas, F. J., Sandalio, L. M., Palma, J. M., Gómez, M., and Barroso, J. B. (2002). Reactive oxygen species, antioxidant systems and nitric oxide in peroxisomes. J. Exp. Bot. 53, 1255-1272. doi: 10.1093/jexbot/53.break372.1255

del Río, L. A., Palma, J. M., Sandalio, L. M., Corpas, F. J., Pastori, G. M., Bueno, P., et al. (1996). Peroxisomes as a source of superoxide and hydrogen peroxide in stressed plants. Biochem. Soc. Trans. 24, 434-438.

del Río, L. A., Pastori, G. M., Palma, J. M., Sandalio, L. M., Sevilla, F., Corpas, F. J., et al. (1998). The activated oxygen role of peroxisomes in senescence. Plant Physiol. 116, 1195-1200. doi: 10.1104/pp.116.4.1195

del Río, L. A., Sandalio, L. M., Altomare, D. A., and Zilinskas, B. A. (2003). Mitochondrial and peroxisomal manganese superoxide dismutase: differential expression during leaf senescence. J. Exp. Bot. 54; 923-933. doi: 10.1093/jxb/erg091

del Río, L. A., Sandalio, L. M., Palma, J. M., Bueno, P., and Corpas, F. J. (1992). Metabolism of oxygen radicals in peroxisomes and cellular implications. Free Radic. Biol. Med. 13, 557-580. doi: 10.1016/0891-5849(92)90150-F

de Pinto, M. C., Paradiso, A., Leonetti, P., and de Gara, L. (2006). Hydrogen peroxide, nitric oxide and cytosolic ascorbate peroxidase at the crossroad between defence and cell death. Plant J. 48, 784-795. doi: 10.1111/j.1365-313X.2006.02919.x

Diaz Vivancos, P., Wolff, T., Markovic, J., Pallardó, F. V., and Foyer, C. H. (2010). A nuclear glutathione cycle within the cell cycle. Biochem. J. 431, 169-178. doi: 10.1042/BJ20100409

Dietz, K. J., Jacob, S., Oelze, M. L., Laxa, M., Tognetti, V., de Miranda, S. B., et al. (2006). The function of peroxiredoxin in plant organelle redox metabolism. J. Exp. Bot. 57, 1697-1709. doi: 10.1093/jxb/erj160

Ding, M., Hou, P., Shen, X., Wang, M., Deng, S., Sun, J., et al. (2010). Salt-induced expression of genes related to $\mathrm{Na}+/ \mathrm{K}+$ and ROS homeostasis in leaves of saltresistant and salt-sensitive poplar species. Plant Mol. Biol. 73, 251-269. doi: 10.1007/s11103-010-9612-9

Dos Santos, C. V., and Rey, P. (2006). Plant thioredoxins are key actors in the oxidative stress response. Trends Plant Sci. 11, 329-334. doi: 10.1016/j.tplants.2006.05.005

Douce, R., Bourguignon, J., Neuburger, M., and Rébeillé, F. (2001). The glycine decarboxylase system: a fascinating complex. Trends Plant Sci. 6, 167-176. doi: 10.1016/S1360-1385(01)01892-1

Duchêne, A. M., and Giegé, P. (2012). Dual localized mitochondrial and nuclear proteins as gene expression regulators in plants? Front. Plant Sci. 3:221. doi: 10.3389/fpls.2012.00221

Dudkina, N. V., Heinemeyer, J., Sunderhaus, S., Boekema, E. J., and Braun, H. P. (2006). Respiratory chain supracomplexes in the plant mitochondria membrane. Trends Plant Sci. 11, 232-240. doi: 10.1016/j.tplants.2006.03.007

Echalier, A., Trivelli, X., Corbier, C., Rouhier, N., Walker, O., Tsan, P., et al. (2005). Crystal structure and resolution NMR dynamics of a D (type II) peroxiredoxin glutaredoxin and thioredoxin dependent: a new insight into the peroxiredoxin oligomerism. Biochemistry 44, 1755-1767. doi: 10.1021/bi04 $8226 \mathrm{~s}$

Edwards, E. A., Rawsthorne, S., and Mullineux, P. M. (1990). Subcellular distribution of multiple forms of glutathione reductase in leaves of pea (Pisum sativum L.) Planta 180, 278-284. doi: 10.1007/BF00194008

Eltayeb, A. E., Kawano, N., Badawi, G. H., Kaminaka, H., Sanekata, T., Shibahara, T., et al. (2007). Overexpression of monodehydroascorbate reductase in transgenic tobacco confers enhanced tolerance to ozone, salt and polyethylene glycol stresses. Planta 225, 1255-1264. doi: 10.1007/s00425-006-0417-7

Eltayeb, A. E., Yamamoto, S., Habora, M. E. E., Yin, L., Tsujimoto, H., and Tanaka, K. (2011). Transgenic potato overexpressing Arabidopsis cytosolic AtDHAR1 showed higher tolerance to herbicide, drought and salt stresses. Breed. Sci. 61, 3-10. doi: $10.1270 /$ jsbbs.61.3

Evrard, C., Capron, A., Marchand, C., Clippe, A., Wattiez, R., Soumillion, P., et al. (2004). Crystal structure of a dimeric oxidized form of human peroxiredoxin 5 . J. Mol. Biol. 337, 1079-1090. doi: 10.1016/j.jmb.2004.02.017

Fares, A., Rossignol, M., and Peltier, J. B. (2011). Proteomics investigation of endogenous S-nitrosylation in Arabidopsis. Biochem. Biophys. Res. Commun. 416, 331-336. doi: 10.1016/j.bbrc.2011.11.036

Fernández-García, N., Martí, M. C., Jiménez, A., Sevilla, F., and Olmos, E. (2009). Sub-cellular distribution of glutathione in an Arabidopsis mutant (vtc1) deficient in ascorbate. J. Plant Physiol. 166, 2004-2012. doi: 10.1016/j.jplph.2009.06.006 
Filipovic, M. R., Stanic, D., Raicevic, S., Spasic, M., and Niketic, V. (2007). Consequences of MnSOD interactions with nitric oxide: nitric oxide dismutation and the generation of peroxynitrite and hydrogen peroxide. Free Radic. Res. 4, 62-72. doi: 10.1080/10715760600944296

Filipou, P., Antoniou, C., and Fotopoulus, V. (2011). Effect of drought and rewatering on the cellular status and antioxidant response of Medicago truncatula plants. Plant Signal. Behav. 6, 270-277. doi: 10.4161/psb.6.2.14633

Finkel, T. (2011). Signal transduction by reactive oxygen species. J. Cell Biol. 194, 7-15. doi: 10.1083/jcb.201102095

Finkemeier, I., Goodman, M., Lankemeyer, P., Kandlbinder, A., Sweetlove, L. J., and Dietz, K. J. (2005). The mitochondrial type II peroxiredoxin $\mathrm{F}$ is essential for redox homeostasis and root growth of Arabidopsis thaliana under stress. J. Biol. Chem. 280, 12168-12180. doi: 10.1074/jbc.M413189200

Foyer, C. H., and Halliwell, B. (1976). Presence of glutathione and glutathione reductase in chloroplasts: a proposed role in ascorbic acid metabolism. Planta 133, 21-25. doi: 10.1007/BF00386001

Foyer, C. H., and Noctor, G. (2005). Redox homeostasis and antioxidant signaling: a metabolic interface between stress perception and physiological responses. Plant Cell 17, 1866-1875. doi: 10.1105/tpc.105.033589

Foyer, C. H., and Noctor, G. (2003). Redox sensing and signalling associated with reactive oxygen in chloroplasts, peroxisomes and mitochondria. Physiol. Plant 119, 355-364. doi: 10.1034/j.1399-3054.2003.00223.x

Foyer, C. H., and Noctor, G. (2009). Redox regulation in photosynthetic organisms: Signaling, acclimation, and practical implications. Antioxid. Redox Signal. 11, 861-905. doi: 10.1089/ars.2008.2177

Foyer, C. H., and Noctor, G. (2011). Ascorbate and glutathione: the heart of the redox hub. Plant Physiol. 155, 2-18. doi: 10.1104/pp.110.167569

Foyer, C. H., Souriau, N., Perret, S., Lelandais, M., Kunert, K. J., Pruvost, C., et al (1995). Overexpression of glutathione reductase but not glutathione synthetase leads to increases in antioxidant capacity and resistance to photoinhibition in poplar trees. Plant Physiol. 109, 1047-1057. doi: 10.1104/pp.109.3.1047

Fröhlich, A., and Durner, J. (2011). The hunt for plant nitric oxide synthase (NOS): is one really needed? Plant Sci. 181, 401-404. doi: 10.1016/j.plantsci.2011. 07.014

Gama, O., Keech, F., Eymery, F., Finkemeier, I., Gelhaye, E., Gardeström, P., et al. (2007). The mitochondrial type II peroxiredoxin from poplar. Physiol. Plant. 129, 196-206. doi: 10.1111/j.1399-3054.2006.00785.x

Gelhaye, E., Rouhier, N., Gérard, J., Jolivet, Y., Gualberto, J., Navrot, N., et al. (2004). A specific form of thioredoxin $\mathrm{h}$ occurs in plant mitochondria and regulates the alternative oxidase. Proc. Natl. Acad. Sci. U.S.A. 101, 14545-14550. doi: 10.1073/pnas.0405282101

Gelhaye, E., Rouhier, N., Navrot, N., and Jaquot, J. P. (2005). The plant thioredoxin system. Cell. Mol. Life Sci. 62, 24-35. doi: 10.1007/s00018-004-4296-4

Gill, S. S., and Tuteja, N. (2010). Reactive oxygen species and antioxidant machinery in abiotic stress tolerance in crop plants. Plant Physiol. Biochem. 48, 909-930. doi: 10.1016/j.plaphy.2010.08.016

Giraud, E., Van Aken, O., Ho, L. H. M., and Whelan, J. (2009). The transcription factor ABI4 is a regulator of mitochondrial retrograde expression of alternative oxidasela. Plant Physiol. 150, 1286-1296. doi: 10.1104/pp.109.139782

Gómez, J. M., Hernández, J. A., Jiménez, A., del Río, L. A., and Sevilla, F. (1999). Differential response of antioxidative enzymes of chloroplasts and mitochondria to long-term $\mathrm{NaCl}$ stress of pea plants. Free Radic. Res. 31, S11-S18. doi 10.1080/10715769900301261

Gómez, J. M., Jiménez, A., Olmos, E., and Sevilla, F. (2004). Location and effects of long-term $\mathrm{NaCl}$ stress on superoxide dismutase and ascorbate peroxidase isoenzymes of pea (Pisum sativum cv. Puget) chloroplasts. J. Exp. Bot. 55, 119-130. doi: $10.1093 /$ jxb/erh013

Gould, K. S., Lamotte, O., Klinuer, A., Pugin, A., and Wendehenne, D. (2003). Nitric oxide production in tobacco leaf cells: a generalized stress response? Plant Cell Environ. 26, 1851-1862. doi: 10.1046/j.1365-3040.2003.01101.x

Guo, F. Q., and Crawford, N. M. (2005). Arabidopsis nitric oxide synthasel is targeted to mitochondria and protects against oxidative damage and dark-induced senescence. Plant Cell 17, 3436-3450. doi: 10.1105/tpc.105.037770

Gupta, K. J. (2011). Protein S-nitrosylation in plants: photorespiratory metabolism and NO signaling. Sci. Signal. 4, jc1. doi: 10.1126/scisignal.2001404

Gupta, K. J., and Igamberdiev, A. U. (2011). The anoxic plant mitochondrion as a nitrite: NO reductase. Mitochondrion 11, 537-543. doi 10.1016/j.mito.2011.03.005
Gupta, K. J., Igamberdiev, A. U., Manjunatha, G., Segu, S., Moran, J. F., Neelawarne, B., et al. (2011). The emerging roles of nitric oxide (NO) in plant mitochondria. Plant Sci. 181, 520-526. doi: 10.1016/j.plantsci.2011.03.018

Gupta, K. J., and Kaiser, W. M. (2010). Production and scavenging of nitric oxide by barley root mitochondria. Plant Cell Physiol. 51, 576-584. doi: $10.1093 / \mathrm{pcp} / \mathrm{pcq} 022$

Hamilton, E. W., and Heckathorn, S. A. (2001). Mitochondrial adaptations to NaCl. Complex I is protected by anti-oxidants and small heat shock proteins, whereas Complex II is protected by proline and betaine. Plant Physiol. 126, 1266-1274. doi: $10.1104 / \mathrm{pp} .126 .3 .1266$

Hartl, M., and Finkemeier, I. (2012). Plant mitochondrial retrograde signaling: translational modifications enter the stage. Front. Plant Sci. 3:253. doi: $10.3389 /$ fpls. 2012.00253

Heazlewood, J. L., Verboom, R. E., Tonti-Filippini, J., Small, I., and Millar, A. H. (2007). SUBA: the Arabidopsis subcellular database. Nucleic Acids Res. 35, D213-D218. doi: 10.1093/nar/gkl863

Hefny, M., and Abdel-Kader, D. Z. (2009). "Antioxidant-enzyme system as selection criteria for salt tolerance in forage sorghum genotypes (Sorghum bicolor L. Moench)," in Salinity and Water Stress, eds M. Ashraf, M. Ozturk, and H. R. Athar (The Netherlands: Springer), 25-36. doi: 10.1007/978-1-4020-9065-3_3

Hernández, J. A., Corpas, F. J., Gómez, M., del Río, L. A., and Sevilla, F. (1993). Salt-induced oxidative stress mediated by activated oxygen species in pea leaf mitochondria. Physiol. Plant. 89, 103-108. doi: 10.1111/j.13993054.1993.tb01792.x

Hernández, J. A., Ferrer, M. A., Jiménez, A., Barceló, A. R., and Sevilla, F. (2001). Antioxidant systems and $\mathrm{O}_{2}{ }^{\bullet-} / \mathrm{H}_{2} \mathrm{O}_{2}$ production in the apoplast of pea leaves. Its relation with salt-induced necrotic lesions in minor veins. Plant Physiol. 127, 817-831. doi: 10.1104/pp.010188

Hernández, J. A., Jiménez, A., Mullineaux, P., and Sevilla, F. (2000). Tolerance of pea (Pisum sativum L.) to long-term salt stress is associated with induction of antioxidant defenses. Plant Cell Environ. 23, 853-862. doi: 10.1046/j.13653040.2000.00602.x

Hess, D. T., Matsumoto, A., Kim, S.-O., Marshall, H. E., and Stamler, J. S. (2005). Protein S-nitrosylation: purview and parameters. Nat. Rev. Mol. Cell Biol. 6, 150-166. doi: 10.1038/nrm1569

Hess, D. T., and Stamler, J. S. (2012). Regulation by S-nitrosylation of protein post-translational modification. J. Biol. Chem. 287, 4411-4418. doi: 10.1074/jbc.R111.285742

Hirota, K., Matsui, M., Iwata, S., Nishiyama, A., Mori, K., and Yodoi, J. (1997). AP-1 transcriptional activity is regulated by a direct association between thioredoxin and Ref-1. Proc. Natl. Acad. Sci. U.S.A. 94, 3633-3638. doi: 10.1073/pnas.94.8.3633

Horling, F., König, J., and Dietz, K.-J. (2002). Type II peroxiredoxin C, a member of the peroxiredoxin family of Arabidopsis thaliana: its expression and activity in comparison with other peroxiredoxins. Plant Physiol. Biochem. 40, 491-499. doi: 10.1016/S0981-9428(02)01396-7

Horling, F., Lamkemeyer, P., König, J., Finkemeier, I., Kandlbinder, A., Baier, M., et al. (2003). Divergent light-, ascorbate-, and oxidative stress-dependent regulation of expression of the peroxiredoxin gene family in Arabidopsis. Plant Physiol. 131, 317-325. doi: 10.1104/pp.010017

Huang, X., von Rad, U., and Durner, J. (2002). Nitric oxide induces transcriptional activation of the nitric oxide-tolerant alternative oxidase in Arabidopsis suspension cells. Planta 215, 914-923. doi: 10.1007/s00425-002-0828-Z

Iglesias-Baena, I., Barranco-Medina, S., Lázaro-Payo, A., López-Jaramillo, F. J., Sevilla, F., and Lázaro, J. J. (2010). Characterization of plant sulfiredoxin and role of sulphinic form of 2-Cys peroxiredoxin. J. Exp. Bot. 6, 1509-1521. doi: 10.1093/jxb/erq016

Iglesias-Baena, I., Barranco-Medina, S., Sevilla, F., and Lázaro, J. J. (2011). The dual targeted plant sulfiredoxin retroreduces the sulfinic form of atypical mitochondrial peroxiredoxin. Plant Physiol. 155, 944-955. doi: 10.1104/pp.110. 166504

Jacoby, R. P., Millar, A. H., and Taylor, N. L. (2010). Wheat mitochondrial proteomes provide new links between antioxidant defense and plant salinity tolerance. $J$. Proteome Res. 9, 6595-6604. doi: 10.1021/pr1007834

Jaspers, P. J., and Kangasjärvi, J. (2010). Reactive oxygen species in abiotic stress signaling. Physiol. Plant. 139, 405-413. doi: 10.1111/j.1399-3054.2009.01321.x

Jeong, W., Park, S. J., Chang, T. S., Lee, D. Y., and Rhee, G. S. (2006). Molecular mechanism of the reduction of cysteine sulfinic acid of peroxiredoxin to 
cysteine by mammalian sulfiredoxin. J. Biol. Chem. 281, 14400-14407. doi: 10.1074/jbc.M511082200

Jiang, Y., Yang, B., Harris, N. S., and Deyholos, M. K. (2007). Comparative proteomic analysis of $\mathrm{NaCl}$ stress-responsive proteins in Arabidopsis roots. J. Exp. Bot. 58, 3591-3607. doi: 10.1093/jxb/erm207

Jiménez, A., Hernández, J. A., del Río, L. A., and Sevilla, F. (1997). Evidence for the presence of the ascorbate-glutathione cycle in mitochondria and peroxisomes of pea leaves. Plant Physiol. 114, 275-284.

Jiménez, A., Hernández, J. A., Pastori, G., del Río, L. A., and Sevilla, F. (1998). Role of the ascorbate-glutathione cycle of mitochondria and peroxisomes in the senescence of pea leaves. Plant Physiol. 118, 1327-1335. doi 10.1104/pp.118.4.1327

Jönsson, T. J., and Lowther, W. T. (2007). The peroxiredoxin repair proteins. Subcell. Biochem. 44, 115-141. doi: 10.1007/978-1-4020-6051-9_6

Jönsson, T. J., Murray, M. S., Johnson, L. C., and Lowther, W. T. (2008). Reduction of cysteine sulfinic acid in peroxiredoxin by sulfiredoxin proceeds directly through a sulfinic phosphoryl ester intermediate. J. Biol. Chem. 283, 23846-23851. doi: 10.1074/jbc.M803244200

Kaminaka, H., Morita, S., Tokumoto, M., Masumura, T., and Tanaka, K. (1999). Differential gene expression of rice superoxide dismutase isoforms to oxidative and environmental stresses. Free Radic. Res. 31, S219-S225. doi: $10.1080 / 10715769900301541$

Karplus, P. A., and Hall A. (2007). Structural survey of the peroxiredoxins. Subcell. Biochem. 44, 41-60. doi: 10.1007/978-1-4020-6051-9_3

Kim, K., Kim, I. H., and Lee, K.-Y. (1988). The isolation and purification of a specific "protector" protein which inhibits enzyme inactivation by a thiol/Fe(III)/O2 mixed function oxidation system. J. Biol. Chem. 263, 4704-4711.

Kirby, K., Hu, J., Hilliker, A. J., and Phillips, J. P. (2002). RNA interference-mediated silencing of Sod 2 in Drosophila leads to early adult-onset mortality and elevated endogenous oxidative stress. Proc. Natl. Acad. Sci. U.S.A. 99, 16162-16167. doi: $10.1073 /$ pnas. 252342899

Kirchsteiger, K., Ferrández, J., Pascual, M. B., González, M., and Cejudo, F. J. (2012). NADPH thioredoxin reductase $\mathrm{C}$ is localized in plastids of photosynthetic and nonphotosynthetic tissues and is involved in lateral root formation in Arabidopsis thaliana. Plant Cell 24, 1534-1548. doi: 10.1105/tpc.111. 092304

König, J., Baier, M., Horling, F., Kahmann, U., Harris, G., Schürman, P., et al. (2002) The plant-specific function of 2-Cys peroxiredoxin-mediated detoxification of peroxides in the redox-hierarchy photosynthetic electron flux. Proc. Natl. Acad. Sci. U.S.A. 99, 5738-5743. doi: 10.1073/pnas.072644999

König, J., Lotte, K., Plessow, R., Brockhinke, A., Baier, M., and Dietz, K. J (2003). Reaction mechanism of plant 2-Cys peroxiredoxin. Role of the C terminus and the quaternary structure. J. Biol. Chem. 278, 24409-24420. doi: 10.1074/jbc.M301145200

Kornberg, M. D., Sen, N., Hara, M. R., Juluri, K. R., Nguyen, J. V., Snowman, A. M., et al. (2010). GAPDH mediates nitrosylation of nuclear proteins. Nat. Cell Biol 12, 1094-1100. doi: 10.1038/ncb2114

Koprivova, A., Mugford, S. T., and Kopriva, S. (2010). Arabidopsis root growth dependence on glutathione is linked to auxin transport. Plant Cell Rep. 29, 11571167. doi: 10.1007/s00299-010-0902-0

Kovacs, I., and Lindermayr, C. (2013). Nitric oxide-based protein modification: formation and site-specificity of protein S-nitrosylation. Front. Plant Sci. 4:137. doi: 10.3389/fpls.2013.00137. doi: 10.3389/fpls.2013.00137

Kropotov, A., Serikov, V., Suh, J., Smirnova, A., Bashkirov, V., Zhivotovsky, B., et al. (2006). Constitutive expression of the human peroxiredoxin $\mathrm{V}$ gene contributes to protection of the genome from oxidative DNA lesions and to suppression of transcription of noncoding DNA. FEBS J. 273, 2607-2617. doi: 10.1111/j.17424658.2006.05265.x

Laloi, C., Rayapuram, N., Chartier, Y., Grienenberger, J. M., Bonnard, G., and Meyer, Y. (2001). Identification and characterization of a mitochondrial thioredoxin system in plants. Proc. Natl. Acad. Sci. U.S.A. 98, 14144-14149. doi 10.1073/pnas. 241340898

Leferink, N. G. H., van Duijn, E., Barendregt, A., Heck, A. J. R., and van Berkel, W. J. H. (2009). Galactonolactone dehydrogenase requires a redox-sensitive thiol for optimal production of vitamin C. Plant Physiol. 150, 596-605. doi: $10.1104 /$ pp.109.136929

Leister, D. (2012). Retrograde signaling in plants: from simple to complex scenarios. Front. Plant Sci. 3:135. doi: 10.3389/fpls.2012.00135
Leitner, M., Vandelle, E., Gaupels, F., Bellin, D., and Delledonne, M. (2009). NO signals in the haze. Nitric oxide signalling in plant defence. Curr. Opin. Plant Biol. 12, 451-458. doi: 10.1016/j.pbi.2009.05.012

Lindermayr, C., Saalbach, G., and Durner, J. (2005). Proteomic identification of S-nitrosylated proteins in Arabidopsis. Plant Physiol. 137, 921-930. doi: 10.1104/pp.104.058719

Liu, X. P., Liu, X. Y., Zhang, J., Xia, Z. L., Liu, X., Qin, H. J., et al. (2006). Molecular and functional characterization of sulfiredoxin homologs from higher plants. Cell Res. 16, 287-296. doi: 10.1038/sj.cr.7310036

Lu, Z., Liu, D., and Liu, S. (2007). Two rice cytosolic ascorbate peroxidases differentially improve salt tolerance in transgenic Arabidopsis. Plant Cell Rep. 26, 1909-1917. doi: 10.1007/s00299-007-0395-7

Martí, M. C., Florez-Sarasa, I., Camejo, D., Pallol, B., Ortiz, A., Ribas-Carbó, M., et al. (2012). Response of mitochondrial antioxidant system and respiratory pathways to reactive nitrogen species in pea leaves. Physiol. Plant. 147, 194-206. doi: 10.1111/j.1399-3054.2012.01654.x

Martí, M. C., Florez-Sarasa, I., Camejo, D., Ribas-Carbó, M., Lázaro, J. J., Sevilla, F., et al. (2011). Response of the mitochondrial antioxidant redox system and respiration to salinity in pea plants. J. Exp. Bot. 62, 3863-3874. doi: $10.1093 / \mathrm{jxb} / \mathrm{err} 076$

Martí, M. C., Olmos, E., Calvete, J. J., Díaz, I., Barranc-Medina, S., Whelan, J., et al. (2009). Mitochondrial and nuclear localization of a novel pea thioredoxin: identification of its mitochondrial target proteins. Plant Physiol. 150, 646-657. doi: 10.1104/pp.109.138073

Maxwell, D. P., Wang, Y., and McIntosh, L. (1999). The alternative oxidase lowers mitochondrial reactive oxygen production in plant cells. Proc. Natl. Acad. Sci. U.S.A. 96, 8271-8276. doi: 10.1073/pnas.96.14.8271

Menezes-Benavente, L., Teixeira, F. K., Kamei, C. L. A., and Margis-Pinheiro M. (2004). Salt stress induces altered expression of genes encoding antioxidant enzymes in seedlings of a Brazilian indica rice (Oryza sativa L.). Plant Sci. 166, 323-331. doi: 10.1016/j.plantsci.2003.10.001

Meyer, Y., Belin, C., Delorme-Hinoux, V., Reichheld, J. P., Riondet, C., and Meyer, Y. (2012). Thioredoxin and glutaredoxin systems in plants: molecular mechanisms, crosstalks, and functional significance. Antioxid. Redox Signal. 17, 1124-1160. doi: 10.1089/ars.2011.4327

Mitchell, D. A., and Marletta, M. A. (2005). Thioredoxin catalyzes the S-nitrosation of the caspase-3 active site cysteine. Nat. Chem. Biol. 1, 154-158. doi: $10.1038 /$ nchembio720

Millar, A. H., Considine, M. J., Day, D. A., and Whelan, J. (2001). Unraveling the role of mitochondria during oxidative stress in plants. IUBMB Life 51, 201-205. doi: $10.1080 / 152165401753311735$

Millar, A. H., and Day, D. A. (1996). Nitric oxide inhibits the cytochrome oxidase but not the alternative oxidase of plant mitochondria. FEBS Lett. 398, 155-158. doi: 10.1016/S0014-5793(96)01230-6

Millar, A. H., Mittova, V., Kiddle, G., Heazlewood, J. L., Bartoli, C. G., Theodoulou, F. L., et al. (2003). Control of ascorbate synthesis by respiration and its implications for stress responses. Plant Physiol. 133, 443-447. doi: 10.1104/pp.103.028399

Millar, A. H., Whelan, J., Soole, K. L., and Day, D. A. (2011). Organization and regulation of mitochondrial respiration in plants. Annu. Rev. Plant Biol. 62, 79-104. doi: 10.1146/annurev-arplant-042110-103857

Mittler, R., Vanderauwera, S., Suzuki, N., Miller, G., Tognetti, V. B., Vandepoele, K., et al. (2011). ROS signaling: the new wave? Trends Plant Sci. 16, 300-309. doi: 10.1016/j.tplants.2011.03.007

Mitschke, J., Fuss, J., Blum, T., Höglund, A., Reski, R., Kohlbacher, O., et al. (2009). Prediction of dual protein targeting to plant organelles. New Phytol. 183, 224-235. doi: 10.1111/j.1469-8137.2009.02832.x

Mittova, V., Guy, M., Tal, M., and Volokita, M. (2004). Salinity up-regulates the antioxidative system in root mitochondria and peroxisomes of the wild salttolerant tomato species Lycopersicon pennellii. J. Exp. Bot. 55, 1105-1113. doi: $10.1093 / \mathrm{jxb} / \mathrm{erh} 113$

Mittova, V., Tal, M., Volokita, M., and Guy, M. (2003). Up-regulation of the leaf mitochondrial and peroxisomal antioxidative systems in response to salt-induced oxidative stress in the wild salt-tolerant tomato species Lycopersicon pennellii. Plant Cell Environ. 26, 845-856. doi: 10.1046/j.1365-3040.2003. 01016.x

Moller, I. M. (2001). Plant mitocondria and oxidative stress: electron transport, NADPH turnover and metabolism of reactive oxygen species. Annu. Rev. Plant Physiol. Plant Mol. Biol. 52, 561-591. doi: 10.1146/annurev.arplant.52.1.561 
Morgan, M. J., Lehmann, M., Schwarzländer, M., Baxter, C. J., SienkiewiczPorzucek, A., Williams, T. C. R., et al. (2008). Decrease in manganese superoxide dismutase leads to reduced root growth and affects tricarboxylic acid cycle flux and mitochondrial redox homeostasis. Plant Physiol. 147, 101-114. doi: $10.1104 / p p .107 .113613$

Mullineaux, P. M., and Rausch, T. (2005). Glutathione, photosynthesis and the redox regulation of stress-responsive gene expression. Photosynth. Res. 86, 459-474. doi: 10.1007/s11120-005-8811-8

Munné-Bosch, S., Queval, G., and Foyer, C. H. (2013). The impact of global change factors on redox signaling underpinning stress tolerance. Plant Physiol. 161, 5-19. doi: 10.1104/pp.112.205690

Neill, S. J., Desikan, R., and Hancock, J. T. (2003). Nitric oxide signalling in plants New Phytol. 159, 11-35. doi: 10.1046/j.1469-8137.2003.00804.x

Noctor, G., De Paepe, R., and Foyer, C. H. (2007). Mitochondrial redox biology and homeostasis in plants. Trends Plant Sci. 12, 125-134. doi: 10.1016/j.tplants.2007.01.005

Noctor, G., and Foyer, C. H. (1998). Ascorbate and glutathione: keeping active oxygen under control. Annu. Rev. Plant Physiol. Plant Mol. Biol. 49, 249-279. doi: 10.1146/annurev.arplant.49.1.249

Noctor, G., Mhamdi, A., Chaouch, S., Han, Y., Neukermans, J., Marquez-Garcia, B., etal. (2012). Glutathione in plants: an integrated overview. Plant Cell Environ. 35, 454-484. doi: 10.1111/j.1365-3040.2011. 02400.x

Noh, Y. H., Baek, J. Y., Jeong, W., Rhee, S. G., and Chang, T. S. (2009). Sulfiredoxin translocation into mitochondria plays a crucial role in reducing hyperoxidized peroxiredoxin III. J. Biol. Chem. 284, 8470-8477. doi: 10.1074/jbc.M808981200

Obara, K., Sumi, K., and Fukuda, H. (2002). The use of multiple transcription starts causes the dual targeting of Arabidopsis putative monodehydroascorbate reductase to both mitochondria and chloroplasts. Plant Cell Physiol. 43, 697-705. doi: $10.1093 / \mathrm{pcp} / \mathrm{pcf} 103$

Olmos, E., Hernández, J. A., Sevilla, F., and Hellín, E. (1994). Induction of several antioxidant enzymes in the selection of a salt-tolerant cell-line of Pisum sativum. J. Plant Physiol. 144, 594-598. doi: 10.1016/S0176-1617(11) 82142-5

O’Neill, J. S., and Reddy, A. B. (2011). Circadian clocks in human red blood cells. Nature 469, 498-504. doi: 10.1038/nature09702

Ortega-Galisteo, A. P., Rodríguez-Serrano, M., Pazmino, D. M., Gupta, D. K., Sandalio, L. M., and Romero-Puertas, M. C. (2012). S-nitrosylated proteins in pea (Pisum sativum L.) leaf peroxisomes: changes under abiotic stress. J. Exp. Bot. 63, 2089-2103. doi: 10.1093/jxb/err414

Pallanca, J. E., and Smirnoff, N. (2000). The control of ascorbic acid synthesis and turnover pea seedlings. J. Exp. Bot. 51, 669-674. doi: 10.1093/jexbot/51.345.669

Palma, J. M., Jiménez, A., Sandalio, L. M., Corpas, F. J., Lundqvist, M., Gómez, M., et al. (2006). Antioxidative enzymes from chloroplasts, mitochondria and peroxisomes during leaf senescence of nodulated pea plants. J. Exp. Bot. 57 , 1747-1758. doi: 10.1093/jxb/erj191

Palmieri, M. C., Lindermayr, C., Bauwe, H., Steinhauser, C., and Durner J. (2010). Regulation of plant glycine decarboxylase by S-nitrosylation and glutathionylation. Plant Physiol. 152, 1514-1528. doi: 10.1104/pp.109. 152579

Pascual, M. B., Mata-Cabana, A., Florencio, F. J., Lindahl, M., and Cejudo, F. J. (2010). Overexpresion of 2-Cys peroxiredoxin in prokariotes: cyanobacterial 2 Cys peroxiredoxins sensitive to oxidative stress. J. Biol. Chem. 285, 34485-34492. doi: 10.1074/jbc.M110.160465

Pastore, D., Trono, D., Laus, M. N., Di Fonzo, N., and Flagella, Z. (2007). Possible plant mitochondria involvement in cell adaptation to drought stress. A case study: durum wheat mitochondria. J. Exp. Bot. 58, 195-210. doi: 10.1093/jxb/erl273

Pérez-Ruiz, J. M., Spinola, M. C., Kirchsteiger, K., Moreno, J., Sahrawy, M., and Cejudo, F. J. (2006). Rice NTRC is a high-efficiency redox system for chloroplast protection against oxidative damage. Plant Cell 18, 2356-2368. doi: 10.1105/tpc.106.041541

Pineau, B., Layoune, O., Danon, A., and De Paepe, R. (2008). L-Galactono-1,4lactone dehydrogenase is required for the accumulation of plant respiratory complex I. J. Biol. Chem. 283, 32500-32505. doi: 10.1074/jbc.M805320200

Planchet, E., Gupta, K. J., Sonoda, M., and Kaiser, W. M. (2005). Nitric oxide emission from tobacco leaves and cell suspensions: rate limiting factors and evidence for their involvement of mitochondrial electron transport. Plant J. 41 732-743. doi: 10.1111/j.1365-313X.2005.02335.x
Poderoso, J. J., Carreras, M. C., Lisdero, C., Riobó, N., Schöpfer, F., and Boveris, A. (1996). Nitric oxide inhibits electron transfer and increases superoxide radical production in rat heart mitochondria and submitochondrial particles. Arch. Biochem. Biophys. 328, 85-92. doi: 10.1006/abbi.1996.0146

Potters, G., De Gara, L., Asard, H., and Horemans, N. (2002). Ascorbate and glutathione: guardians of the cell cycle, partners in crime? Plant Physiol. Biochem. 40, 537-548. doi: 10.1016/S0981-9428(02)01414-6

Pujol, C., Maréchal-Drouard, L., and Duchêne, A. M. (2007). How can organellar protein $\mathrm{N}$-terminal sequences be dual targeting sigmals? In silico analysis and mutagenesis approach. J. Mol. Biol. 369, 356-367. doi: 10.1016/j.jmb.2007. 03.015

Pulido, P., Cazalis, R., and Cejudo, F. J. (2009). An antioxidant redox system in the nucleus of wheat seed cells suffering oxidative stress. Plant J. 57, 132-145. doi: 10.1111/j.1365-313X.2008.03675.x

Pulido, P., Spinola, M. C., Kirchsteiger, K., Guinea, M., Pascual, M. B., Sahrawy, M., et al. (2010). Functional analysis of the pathways for 2-Cys peroxiredoxin reduction in Arabidopsis thaliana chloroplasts. J. Exp. Bot. 61, 4043-4054. doi: 10.1093/jxb/erq218

Puppo, A., Groten, K., Bastian, F., Carzaniga, R., Soussi, M., Lucas, M. M., et al. (2005). Legume nodule senescence: roles for redox and hormone signalling in the orchestration of the natural aging process. New Phytol. 165, 683-701. doi: 10.1111/j.1469-8137.2004.01285.x

Rasmusson, A. G., Fernie, A. R., and van Dongen, J. T. (2009). Alternative oxidase: a defence against metabolic fluctuations? Physiol. Plant. 137, 371-382. doi: 10.1111/j.1399-3054.2009.01252.x

Rasmusson, A. G., and Moller, I. M. (1991). NAD(P)H dehydrogenases on the inner surface of the inner mitochondrial membrane studied using insideout submitochondriral particles. Physiol. Plant. 83, 357-365. doi: 10.1111/j.13993054.1991.tb00106.x

Rasmusson, A. G., and Wallström, S. V. (2010). Involvement of mitochondria in the control of plant cell NAD(P)H reduction levels. Biochem. Soc. Trans. 38, 661-666. doi: 10.1042/BST0380661

Reichheld, J. P., Meyer, E., Khafif, M., Bonnard, G., and Meyer, Y. (2005). AtNTRB is the major mitochondrial thioredoxin reductase in Arabidopsis thaliana. FEBS Lett. 579, 337-342. doi: 10.1016/j.febslet.2004.11.094

Rey, P., Becuwe, N., Barrault, M. B., Rumeau, D., Havaux, M., Biteau, B., et al. (2007). The Arabidopsis thaliana sulfiredoxin is a plastidic cysteine-sulfinic acid reductase involved in the photooxidative stress response. Plant J. 49, 505-514. doi: 10.1111/j.1365-313X.2006.02969.x

Rhee, S. G. (2006). H2O2, a necessary evil for cell signalling. Science 312, 1882-1883. doi: $10.1126 /$ science. 1130481

Rhee, S. G., Chae, H. Z., and Kim, K. (2005). Peroxiredoxins: a historical overview and speculative preview of novel mechanism and emerging concepts in cell signalling. Free Radic. Biol. Med. 38, 1543-1552. doi: 10.1016/ j.freeradbiomed.2005.02.026

Rhoads, D. M., and Subbaiah, C. C. (2007). Mitochondrial retrograde regulation in plants. Mitochondrion 7, 177-194. doi: 10.1016/j.mito.2007.01.002

Ribas-Carbó, M., Robinson, S. A., and Giles, L. (2005). "The application of the oxygen-isotope technique to assess respiratory pathway partitioning," in Advances in Photosynthesis and Respiration. Plant Respiration: from Cell to Ecosystem, eds H. Lambers and M. Ribas-Carbó (The Netherlands: Springer), 18, 31-42.

Rodríguez-Serrano, M., Romero-Puertas, M. C., Pazmiño, D. M., Testillano, P. S., Risueño, M. C., Del Río, L. A., et al. (2009). Cellular response of pea plants to cadmium toxicity: cross talk between reactive oxygen species, nitric oxide, and calcium. Plant Physiol. 150, 229-243. doi: 10.1104/pp.108.131524

Romero-Puertas, M. C., Campostrini, N., Mattè, A., Righetti, P. G., Perazzolli, M., Zolla, L., et al. (2008). Proteomic analysis of S-nitrosylated proteins in Arabidopsis thaliana undergoing hypersensitive response. Proteomics 8, 1459- 1469. doi: 10.1002/pmic.200700536

Romero-Puertas, M. C., Laxa, M., and Delledonne, M. (2007). S-nitrosylation of peroxiredoxin II E promotes peroxynitrite-mediated tyrosine nitration. Plant Cell 19, 4120-4130. doi: 10.1105/tpc.107.055061

Rouhier, N., Gelhaye, E., and Jacquot, J. P. (2002). Glutaredoxin-dependent peroxiredoxin from poplar: protein-protein interaction and catalytic mechanism. J. Biol. Chem. 277, 13609-13614. doi: 10.1074/jbc.M111489200

Rouhier, N., and Jacquot, J. P. (2005). The plant multigenic family of thiol peroxidases. Free Radic. Biol. Med. 38, 1413-1421. doi: 10.1016/ j.freeradbiomed.2004.07.037 
Rouhier, N., Lemaire, S. D., and Jacquot, J. P. (2008). The role of glutathione in photosynthetic organisms: emerging functions for glutaredoxins and glutathionylation. Annu. Rev. Plant Biol. 59, 143-166. doi: 10.1146/ annurev.arplant.59.032607.092811

Roussel, X., Kriznik, A., Richard, C., Rauel-Clermont, S., and Branlsant, G. (2009) Catalytic mechanism of sulfiredoxin from Saccharomyces cerevisiae passes through an oxidized disusfide sulfiredoxin intermediate that is reduced by thioredoxin. $J$. Biol. Chem. 284, 33048-33055. doi: 10.1074/jbc.M109.035352

Rubio, M. C., Bustos-Sanmamed, P., Clemente, M. R., and Becana, M. (2009) Effects of salt stress on the expression of antioxidant genes and proteins in the model legume Lotus japonicas. New Phytol. 181, 851-859. doi: 10.1111/j.14698137.2008.02718.x

Sairam, R. K., and Srivastava, G. C. (2002). Changes in antioxidant activity in subcellular fractions of tolerant and susceptible wheat genotypes in response to long -term salt stress. Plant Sci. 162, 897-904. doi: 10.1016/S0168-9452(02)00037-7

Saitoh, M., Nishitoh, H., Fujii, M., Takeda, K., Tobiume, K., Sawada, Y., et al. (1998). Mammalian thioredoxin is a direct inhibitor of apoptosis signal-regulating kinase (ASK) 1. EMBO J. 17, 2596-2606. doi: 10.1093/emboj/17.9.2596

Schwarzländer, M., and Finkemeier, I. (2013). Mitochondrial energy and redox signaling in plants. Antioxid. Redox Signal. 18, 2122-2144. doi: 10.1089/ars.2012.5104

Seo, M. S., Kang, S. W., Kim, K., Baines, I. C., Lee, T. H., and Rhee, S. G. (2000). Identification of a new type of mammalian peroxiredoxin that forms an intramolecular disulfide as a reaction intermediate. J. Biol. Chem. 275, 20346-20354. doi 10.1074/jbc.M001943200

Serrato, A. J., and Cejudo, F. J. (2003). Type-H Thioredoxins accumulate in the nucleus of developing wheat seed tissues suffering oxidative stress. Planta 217, 392-399. doi: 10.1007/s00425-003-1009-4

Serrato, A. J., Crespo, J. L., Florencio, F. J., and Cejudo, F. J. (2001). Characterization of two thioredoxins $\mathrm{h}$ with predominant localization in the nucleus of aleurone and scutellum cells of germinating wheat seeds. Plant Mol. Biol. 46, 361-371. doi: 10.1023/A:1010697331184

Serrato, A. J., Pérez-Ruiz, J. M., Spínola, M. C., and Cejudo, F. J. (2004). A novel NADPH thioredoxin reductase, localized in the chloroplast, which deficiency causes hypersensitivity to abiotic stress in Arabidopsis thaliana. J. Biol. Chem. 279, 43821-43827. doi: 10.1074/jbc.M404696200

Sevilla, F., López-Gorgé, J., and del Río, L. A. (1982). Characterization of a manganese superoxide dismutase from the higher plant Pisum sativum. Plant Physiol. 70, 1321-1326. doi: 10.1104/pp.70.5.1321

Sharma, P., and Dubey, R. S. (2005). Drought induces oxidative stress and enhances the activities of antioxidant enzymes in growing rice seedlings. Plant Growt Regul. 46, 209-221. doi: 10.1007/s10725-005-0002-2

Smith, C. A., Melino, V. J., Sweetman, C., and Soole, K. L. (2009). Manipulation of alternative oxidase can influence salt tolerance in Arabidopsis thaliana. Physiol. Plant. 137, 459-472. doi: 10.1111/j.1399-3054.2009.01305.x

Szarka, A., Horemans, N., Kovacs, Z., Gróf, P., Mayer, M., and Bánhegyi, G. (2007). Dehydroascorbate reduction in plant mitochondria is coupled to the respiratory electron transfer chain. Physiol. Plant. 129, 225-232. doi: 10.1111/j.1399-3054.2006.00810.x

Talla, S., Riazunnisa, K., Padmavathi, L., Sunil, B., Rajsheel, P., and Raghavendra, A. S. (2011). Ascorbic acid is a key participant during the interactions between chloroplasts and mitochondria to optimize photosynthesis and protect against photoinhibition. J. Biosci. 36, 163-173. doi: 10.1007/s12038-011-9000-x

Tanaka, K., Hibino, T., Hayashi, Y., Tanaka, A., Kishitani, S., Takabe, T., et al. (1999). Salt tolerance of transgenic rice overexpression yeast mitochondrial Mn-SOD in chloroplasts. Plant Sci. 148, 131-138. doi: 10.1016/S0168-9452(99)00133-8

Tanaka, T., Hosoi, F., Yamaguchi-Iwai, Y., Nakamura, H., Masutani, H., Ueda, S., et al. (2002). Thioredoxin-2 (TRX-2) is an essential gene regulating mitochondria dependent apoptosis. EMBO J. 21, 1695-1703. doi: 10.1093/emboj/21.7.1695

Tanou, G., Job, C., Rajjou, L., Arc, E., Belghazi, M., Diamantidis, G., et al. (2009). Proteomics reveals the overlapping roles of hydrogen peroxide and nitric oxide in the acclimation of citrus plants to salinity. Plant J. 60, 795-804. doi: 10.1111/j.1365-313X.2009.04000.x

Taylor, E. R., Hurrell, F., Shannon, R. J., Lin, T. K., Hirst, J., and Murphy, M. P. (2003). Reversible glutathionylation of complex I increases mitochondrial superoxide formation. J. Biol. Chem. 278, 19603-19610. doi: 10.1074/jbc.M209359200

Taylor, N. L., Tan, Y.-F., Jacoby, R. P., and Millar, A. H. (2009). Abiotic environmental stress induced changes in the Arabidopsis thaliana chloroplast, mitochondria and peroxisome proteomes. J. Proteomics 72, 367-378. doi: 10.1016/j.jprot.2008.11.006

Teixeira, F. K., Menezes-Benavente, L., Galvao, V. C., Margis, R., and MargisPinheiro, M. (2006). Rice ascorbate peroxidase gene family encodes functionally diverse isoforms localized in different subcellular compartments. Planta 224, 300-314. doi: 10.1007/s00425-005-0214-8

Tovar-Méndez, A., Matamoros, M. A., Bustos-Sanmamed, P., Dietz, K. J., Cejudo, F. J., Rouhier, N., et al. (2011). Peroxiredoxins and NADPH-dependent thioredoxin systems in the model legume Lotus japonicas. Plant Physiol. 156, 1535-1547. doi: 10.1104/pp.111.177196

Tripathi, B. N., Bhatt, I., and Dietz, K. J. (2009). Peroxiredoxins: a less studied component of hydrogen peroxide detoxification in photosynthetic organisms. Protoplasma 235, 3-15. doi: 10.1007/s00709-009-0032-0

Trono, D., Flagella, Z., Laus, M. N., Di Fonzo, N., and Pastore, D. (2004). The uncoupling protein and the potassium channel are activated by hyperosmotic stress in mitochondria from durum wheat seedlings. Plant Cell Environ. 27, 437448. doi: 10.1111/j.1365-3040.2003.01162.x

Turrens, J. F. (2003). Mitochondrial formation of reactive oxygen species. J. Physiol. (Lond.) 552, 335-344. doi: 10.1113/jphysiol.2003.049478

Umbach, A. L., Ng, V. S., and Siedow, J. N. (2006). Regulation of plant alternative oxidase activity: a tale of two cysteines. Biochim. Biophys. Acta 1757, 135-142. doi: 10.1016/j.bbabio.2005.12.005

Vanacker, H., Sandalio, L. M., Jiménez, A., Palma, J. M., Corpas, F. J., Meseger, V., etal. (2006). Roles for redox regulation in leaf senescence in pea plants grown in different sources of nitrogen nutrition. J. Exp. Bot. 57, 1735-1745. doi: 10.1093/jxb/erl012

Van Aken, O., Giraud, E., Clifton, R., and Whelan, J. (2009a). Alternative oxidase: a target and regulator of stress response. Physiol. Plant. 137, 354-361. doi: 10.1111/j.1399-3054.2009.01240.x

Van Aken, O., Zhang, B., Carrie, C., Uggalla, V., Paynter, E., Giraud, E., et al. (2009b). Defining the mitochondrial stress response in Arabidopsis thaliana. Mol. Plant 2, 1310-1324. doi: 10.1093/mp/ssp053

Van Breusegem, F., Vranová, E., Dat, J. F., and Inzé, D. (2001). The role of active oxygen species in plant signal transduction. Plant Sci. 161, 405-414. doi: 10.1016/S0168-9452(01)00452-6

Vandelle, E., and Delledonne, M. (2011). Peroxynitrite formation and function in plants. Plant Sci. 181, 534-539. doi: 10.1016/j.plantsci.2011.05.002

Van Raamsdonk, J. M., and Hekimi, S. (2009). Deletion of the mitochondrial superoxide dismutase sod-2 extends lifespan in Caenorhabditis elegans. PLoS Genet. 5:1000361. doi: 10.1371/journal.pgen.1000361

Veal, E. A., Day, A. M., and Morgan, B. A. (2007). Hydrogen peroxide sensing and signaling. Mol. Cell. 26, 1-14. doi: 10.1016/j.molcel.2007.03.016

Vivancos, A. P., Castillo, E. A., Biteau, B., Nicot, C., Ayté, J., Toledano, M. B., et al. (2005). A cysteine-sulfinic acid in peroxiredoxin regulates $\mathrm{H} 2 \mathrm{O} 2$-sensing by the antioxidant Papl pathway. Proc. Natl. Acad. Sci. U.S.A. 102, 8875-8880. doi: 10.1073/pnas.0503251102

Wang, Y., Qu, G. Z., Li, H. Y., Wu, Y. J., Wang, C., Liu, G. F., et al. (2010a). Enhanced salt tolerance of transgenic poplar plants expressing a manganese superoxide dismutase from Tamarix androssowii. Mol. Biol. Rep. 37, 1119-1124. doi: 10.1007/s11033-009-9884-9

Wang, Z., Xiao, Y., Chen, W., Tang, K., and Zhang, L. (2010b). Increased vitamin C content accompanied by an enhanced recycling pathway confers oxidative stress tolerance in Arabidopsis. J. Integr. Plant Biol. 52, 400-409. doi: 10.1111/j.17447909.2010.00921.x

Wang, Y., Wisniewski, M., Meilan, R., Uratsu, S. L., Cui, M., Dandekar, A., et al. (2007). Ectopic expression of Mn-SOD in Lycopersicon esculentum leads to enhanced tolerance to salt and oxidative stress. J. Appl. Horticul. 9, 3-8.

Wang, Y., Ying, Y., Chen, J., and Wang, X. (2004). Transgenic Arabidopsis overexpressing Mn-SOD enhanced salt-tolerance. Plant Sci. 67, 671-677. doi: 10.1016/j.plantsci.2004.03.032

Wei-Feng, X., Wei-Ming, S., Ueda, A., and Takabe, T. (2008). Mechanisms of salt tolerance in transgenic Arabidopsis thaliana carrying a peroxisomal ascorbate peroxidase gene from barley. Pedosphere 18, 486-495. doi: 10.1016/S10020160(08)60039-9

Wilkins, H. M., Marquardt, K., Lash, L. H., and Linseman, D. A. (2012). Bcl-2 is a novel interacting partner for the 2-oxoglutarate carrier and a key regulator of mitochondrial glutathione. Free Radic. Biol. Med. 52, 410-419. doi: 10.1016/j.freeradbiomed.2011.10.495 
Wilson, I. D., Neill, S. J., and Hancock, J. T. (2008). Nitric oxide synthesis and signaling in plants. Plant Cell Environ. 31, 622-631. doi: 10.1111/j.13653040.2007.01761.x

Winger, A. M., Taylor, N. L., Heazlewood, J. L., Day, D. A., and Millar, A. H. (2007). Identification of intra- and intermolecular disulphide bonding in the plant mitochondrial proteome by diagonal gel electrophoresis. Proteomics 7, 4158-4170. doi: 10.1002/pmic.200700209

Woo, H. A., Bae, S. H., Park, S., and Rhee, S. G. (2009). Sestrin 2 is not a reductase for cysteine sulfinic acid of peroxiredoxins. Antioxid. Redox Signal. 11, 730-745. doi: 10.1089/ars.2008.2360

Woo, H. A., Jeong, W., Chang, T. S., Park, K. J., Park, S. J., Yang, J. S., et al. (2005). Reduction of cysteine sulfinic acid by sulfiredoxin is specific to 2 cys peroxiredoxins. J. Biol. Chem. 280, 3125-3128. doi: 10.1074/jbc.C4004 96200

Woo, H. A., Kang, S. W., Kim, H. K., Yang, K. S., Chae, H. Z., and Rhee, S. G. (2003). Reversible oxidation of the active site cysteine of peroxiredoxins to cysteine sulfinic acid. Inmunoblot detection with antibodies specific for the hyperoxidized cysteine-containing sequence. J. Biol. Chem. 278, 47361-47364. doi: 10.1074/jbc.C300428200

Wood, Z. A., Poole, L. B., and Karplus, P. A. (2003). Peroxiredoxin evolution and the regulation of hydrogen peroxide signalling. Science 300, 650-653. doi: 10.1126/science. 1080405

Woodson, J. D., and Chory, J. (2008). Coordination of gene expression between organellar and nuclear genomes. Nat. Rev. Genet. 9, 383-395. doi: $10.1038 / \mathrm{nrg} 2348$

Wu, C., Parrott, A. M., Fu, C., Liu, T., Marino, S. M., Gladyshev, V. N., et al. (2011). Thioredoxin 1-mediated post-translational modifications: reduction, transnitrosylation, denitrosylation, and related proteomics methodologies. Antioxid. Redox Signal. 15, 2565-2604. doi: 10.1089/ars.2010.3831

Wulff, A., Oliveira, H. C., Saviani, E. E., and Salgado, I. (2009). Nitrite reduction and superoxide-dependent nitric oxide degradation by Arabidopsis mitochondria: influence of external $\mathrm{NAD}(\mathrm{P}) \mathrm{H}$ dehydrogenases and alternative oxidase in the control of nitric oxide levels. Nitric Oxide 21, 132-139. doi: 10.1016/j.niox.2009.06.003

Yamakura, F., Taka, H., Fujimura, T., and Murayama, K. (1998). Inactivation of human manganese-superoxide dismutase by peroxynitrite is caused by exclusive nitration of tyrosine 34 to 3-nitrotyrosine. J. Biol. Chem. 273, 14085-14089. doi: $10.1074 /$ jbc.273.23.14085

Yamane, K., Mitsuya, S., Taniguchi, M., and Miyake, H. (2010). Transcription profiles of genes encoding catalase an ascorbate peroxidase in rice leaf tissues under salinity. Plant Prod. Sci. 13, 164-168. doi: 10.1626/pps.13.164

Yang, K. S., Kang, S. W., Woo, H. A., Hwang, S. C., Chae, H. Z., Kim, K., et al. (2002). Inactivation of human peroxiredoxin I during catalysis as the result of the oxidation of the catalytic site cysteine to cysteine-sulfinic acid. J. Biol. Chem. 277, 38029-38036. doi: 10.1074/jbc.M206626200

Yip, J. Y. H., and Vanlerberghe, G. C. (2001). Mitochondrial alternative oxidase acts to dampen the generation of active oxygen species during a period of rapid respiration induced to support a high rate of nutrient uptake. Physiol. Plant. 112, 327-337. doi: 10.1034/j.1399-3054.2001.1120305.x

Yoshida, K., Noguchi, K., Motohashi, K., and Hisabori, T. (2013). Systematic Exploration of thioredoxin target proteins in plant mitochondria. Plant Cell Physiol. 54, 875-892. doi: 10.1093/pcp/pct037

Zaffagnini, M., Bedhomme, M., Groni, H., Marchand, C. H., Puppo, C., Gontero, B., et al. (2012a). Glutathionylation in the photosynthetic model organism Chlamydomonas reinhardtii: a proteomic survey. Mol. Cell. Proteomics 11, 1-15. doi: 10.1074/mcp.M111.014142

Zaffagnini, M., Bedhomme, M., Marchand, C. H., Morisse, S., Trost, P., and Lemaire, S. D. (2012b). Redox regulation in photosynthetic organisms: focus on glutathionylation. Antioxid. Redox Signal. 16, 567-586. doi: 10.1089/ars.2011.4255

Zheng, C., Jiang, D., Liu, F., Dai, T., Liu, W., Jing, Q., et al. (2009). Exogenous nitric oxide improves seed germination in wheat against mitochondrial oxidative damage induced by high salinity. Environ. Exp. Bot. 67, 222-227. doi: 10.1016/j.envexpbot.2009.05.002

Conflict of Interest Statement: The authors and the associate editor declare that no relationship exists between the editor and the authors. Although some of them have the same affiliation, they do not have any research or projects in common and they belong to different research groups. Moreover, this manuscript was conducted in the absence of any personal, professional, commercial or financial relationships that could be construed as a potential conflict of interest.

Received: 19 July 2013; accepted: 26 October 2013; published online: 28 November 2013.

Citation: Lázaro JJ, Jiménez A, Camejo D, Iglesias-Baena I, Martí MC, Lázaro-Payo A, Barranco-Medina S and Sevilla F (2013) Dissecting the integrative antioxidant and redox systems in plant mitochondria. Effect of stress and S-nitrosylation. Front. Plant Sci. 4:460. doi: 10.3389/fpls.2013.00460

This article was submitted to Plant Physiology, a section of the journal Frontiers in Plant Science.

Copyright (C) 2013 Lázaro, Jiménez, Camejo, Iglesias-Baena, Martí, Lázaro-Payo, Barranco-Medina and Sevilla. This is an open-access article distributed under the terms of the Creative Commons Attribution License (CC BY). The use, distribution or reproduction in other forums is permitted, provided the original author(s) or licensor are credited and that the original publication in this journal is cited, in accordance with accepted academic practice. No use, distribution or reproduction is permitted which does not comply with these terms. 